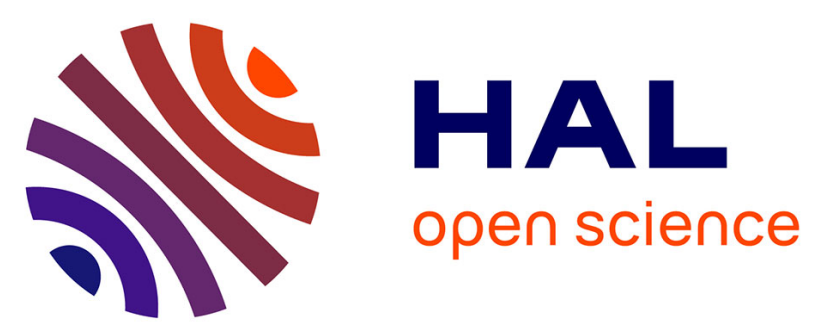

\title{
Stability of a biodegradable microcarrier surface: physically adsorbed versus chemically linked shells
}

Audrey Roy, Maria Alejandra Murcia Valderrama, Valentin Daujat, Khalid Ferji, Michèle Leonard, Alain Durand, Jérôme Babin, Jean-Luc Six

\section{- To cite this version:}

Audrey Roy, Maria Alejandra Murcia Valderrama, Valentin Daujat, Khalid Ferji, Michèle Leonard, et al.. Stability of a biodegradable microcarrier surface: physically adsorbed versus chemically linked shells. Journal of materials chemistry B, 2018, 6 (31), pp.5130-5143. 10.1039/c8tb01255e . hal02058208

\section{HAL Id: hal-02058208 \\ https://hal.univ-lorraine.fr/hal-02058208}

Submitted on 8 Apr 2021

HAL is a multi-disciplinary open access archive for the deposit and dissemination of scientific research documents, whether they are published or not. The documents may come from teaching and research institutions in France or abroad, or from public or private research centers.
L'archive ouverte pluridisciplinaire HAL, est destinée au dépôt et à la diffusion de documents scientifiques de niveau recherche, publiés ou non, émanant des établissements d'enseignement et de recherche français ou étrangers, des laboratoires publics ou privés. 


\section{Stability of biodegradable microcarriers' surface: physically adsorbed versus chemically linked shells}

Received 00th January 20xx, Accepted 00th January 20xx

DOI: $10.1039 / \times 0 \times x 00000 x$

www.rsc.org/

\author{
Audrey ROY ${ }^{a}$, Maria Alejandra MURCIA VALDERRAMA ${ }^{a}$, Valentin DAUJAT ${ }^{a}$, Khalid FERJI ${ }^{a}$, Michèle \\ LEONARD $^{a}$, Alain DURAND ${ }^{a}$, Jérôme BABIN ${ }^{a}$, Jean-Luc SIX ${ }^{\mathrm{a},{ }^{*}}$
}

\begin{abstract}
Mesenchymal Stem Cells (MSCs) are of increasing interest for tissue engineering and cellular therapy. MSCs expansion on microcarriers (MCs) in stirred bioreactor has emerged as an attractive method for their scale-up production. Some MCs have been developed based on polyesters as hydrophobic biodegradable core. However, most of these MCs are formulated with an emulsion/organic solvent evaporation (E/E) process using poly(vinyl alcohol) as shell steric stabilizer, which is biocompatible but not degradable in vivo. Moreover, for most of these MCs, the polymer shell is only physically adsorbed at the particle surface. To the best of our knowledge, no study deals with the stability of such shell when the MCs are in contact with competitive surfactant or with proteins contained in the culture medium. In this study, fully in vivo bioresorbable dextran-covered polylactide-based MCs were formulated using a E/E process, which allowed us to control their surface chemistry. Different dextran derivatives with alkyne or ammonium groups were firstly synthesised. Then, on the one hand, some MCs (non-clicked MCs) were formulated with a physically adsorbed polysaccharidic shell onto the core. On the other hand, the polysaccharidic shell was linked to the core via an in-situ CuAAC click-chemistry carried out during the E/E process (clicked MCs). The stability of such coverages was first studied in the presence of competitive surfactants (sodium dodecyl sulfate-SDS, or proteins contained in culture medium) using nanoparticles (NPs) exhibiting the same chemical composition (core/shell) than MCs. Results showed a total desorption of dextran shell for non-clicked NPs after treatment with SDS or the culture medium, while this shell desorption was greatly decreased for clicked NPs. Qualitative study of this shell stability was finaly carried out on MCs formulated using a new fluorescent dextran-based surfactant. Results were in agreement with those observed for NPs, and showed that non-clicked MCs are characterized by a poor shell stability in contact with a competitive surfactant, which could be quite an issue during MSCs expansion. On the contrary, clicked MCs possess a better shell stability, which allow a better control of the MCs surface chemistry, especially during cell culture.
\end{abstract}

\section{Introduction}

For more than two decades, nano- or micro-sized polymeric particles have been widely studied for various applications such as chemical sensors, coating, chromatography, delivery systems,... ${ }^{1-}$ ${ }^{5 .}$ On the one hand, biodegradable polymeric microparticles ${ }^{6,7}$ or nanoparticles $^{8-10}$ have extensively been reviewed as drug/gene/protein delivery systems, and some of us have reported about biodegradable polylactide (PLA) core/polyethylene glycol (PEG) shell ${ }^{11,12}$ or PLA/dextran shell ${ }^{13-16}$ nanoparticles. On the other hand, polymeric microparticles have also been investigated as microcarriers (MCs) on the surface of which stem cells adhere during their expansion. ${ }^{17}$ Mesenchymal stem cells (MSCs) are multipotent progenitor cells found in bone marrow and other organism sites. While MSCs offer very promising clinical perspectives in regenerative medicine and in cellular therapy ${ }^{18-21}$, MSCs are scarcely present in the organism (1 MSC among $10^{4}$ total

a) Université de Lorraine, CNRS, LCPM, F-54000 Nancy, France

* Corresponding author: Jean-Luc SIX (E-mail: jean-luc.six@univ-lorraine.fr)

+ Electronic Supplementary Information (ESI) available: [details of any supplementary information available should be included here]. See DOI: $10.1039 / x 0 x x 00000 x$ cells in bone marrow $)^{19}$. As large quantities of MSCs $\left(>510^{6}\right.$ MSCs/patient) are required for clinical applications ${ }^{22,23}$, scientists developed reliable MSC expansion via large-scale process requiring MCs. Some MCs, available in the market, are based on polysaccharides such as dextran (e.g. Cytodex-1, Cytodex-3) or cellulose (e.g. Cytopore-2), on gelatin (i.e. CultiSpher-S), or on synthetic polymers such as polystyrene (e.g. Plastic, PlasticPlus, Star Plus, Synthemax ${ }^{\circledR I I)}$ or poly(hydroxylated methacrylate) (e.g. Tosoh 10 PR, Tosoh 65 PR). Commercial MCs also differ in terms of crosslinking, porosity, density, coating and diameter (average diameter around $190 \mu \mathrm{m}$ in case of Cytodex-1). ${ }^{24,25}$ Although commercial MCs have been mainly tested for MSC cultures ${ }^{23,26}$, they are not biodegradable despite their biocompatibility. The resulting MSCs-covered MCs are usually treated with trypsin in order to detach cells and to separate them from the carriers. However, this process may cause significant damages on the viability or phenotype of MSCs for instance ${ }^{27,28}$. To avoid this issue, some biodegradable polyester-based MCs have been developed with either poly(D,L-lactic acid) (PDLLA), poly(L-lactic acid) (PLLA), poly(E-caprolactone) (PCL) or poly(D,L-lactic-co-glycolic acid) $(P L G A)^{29-35}$, which can be transplanted without detachment of the MSCs. However, such biodegradable MCs were formulated using 
poly(vinyl alcohol) (PVA) as stabilizer. Despite that PVA is approved by FDA, known to be biocompatible and degradable in the Nature and soils, it remains unfortunately not degradable in vivo. ${ }^{36}$

The main objective of the present work is to investigate the substitution of PVA by dextran derivatives as biodegradable/biocompatible surfactants to formulate fully in vivo bioresorbable dextran-covered PLA-based MCs. These latter will be produced using emulsion/organic solvent evaporation (E/E) process, and in some experiments the polysaccharide shell will be in-situ attached to the PLA core via an Huisgen-type Copper (I)catalysed Azide-Alkyne Cycloaddition (CuAAC) click-chemistry. By this way, clicked and non-clicked MCs will be thus formulated. It should be noted that we already reported this original process to produce highly stable nanoparticles and nanocapsules ${ }^{13,37,38}$. To this end, several dextran-based surfactants (Fig. 1) were produced. Some of them, carrying several alkyne groups, will be used to achieve the in situ CuAAC reaction when using $\alpha$-azido functionalized PLA (PLA- $\mathrm{N}_{3}$ ) as core. Moreover, to produce MCs with a positively charged surface known to promote cells adhesion $^{29,39,40}$, we also chose to functionalize dextran with some ammoniums as commercial diethylaminoethyl-dextran hydrochloride suffers from serious drawbacks in terms of number and nature of ammoniums.

The main part of this study is then devoted to the MCs' shell stability evaluation in the presence of the culture medium ${ }^{26}$ or SDS
(Sodium DodecylSulfate, a competitive anionic surfactant). While Privalova et al. ${ }^{29}$ studied the effect of the MCs' topography and surface chemistry on the cell behaviour, no paper deals with the MCs' shell stability. Unfortunately, as the shell-based dextran of MCs is very thin ( $\leq 10 \mathrm{~nm}$ compared to average PLA-based MC's diameter of $150-250 \mu \mathrm{m}$ ), it was not possible to directly quantify the polysaccharide amount at the surface of such particles (less than $10 \mathrm{mg}$ of dextran per gram of PLA). Consequently, we selected a fluorescent dextran-based surfactant (Dex-C $\equiv \mathrm{C}$-coumarin, Fig. 2) to indirectly study this stability. In the same time, we formulated nanoparticles (NPs) with the same chemical composition as MCs. With such NPs, the dextran shell thickness was around $12 \mathrm{~nm}$ for an average NPs diameter of $115 \mathrm{~nm}$ and the amount of dextran per gram of PLA was higher than $100 \mathrm{mg}^{37}$, thus making the NPs' shell stability evaluation very easy.

\section{Materials and methods}

\section{Materials}

Dextran T40 $\left(\overline{\mathrm{M}_{\mathrm{n}}}=35,000 \mathrm{~g} \mathrm{~mol}^{-1}\right.$ and $\mathrm{D}=1.2$; values determined by size exclusion chromatography (SEC) coupled to a multi-angle laser light scattering (MALLS) detector in water $\left.(0.1 \mathrm{M} \mathrm{NaNO})_{3}\right)$ ) was purchased from Aldrich and dried under vacuum at $100^{\circ} \mathrm{C}$ for one

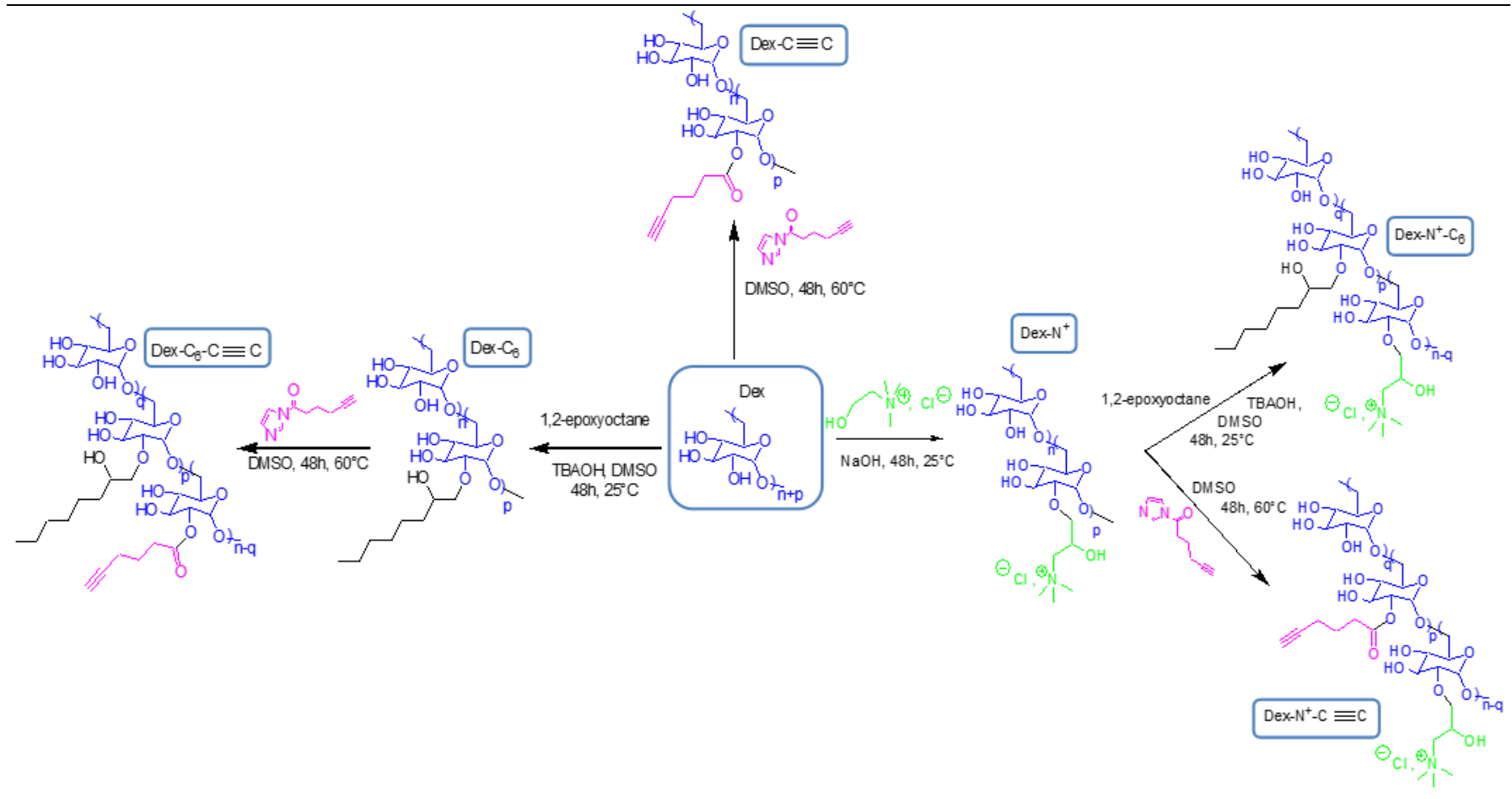

Fig. 1. Structures and syntheses of various dextran derivatives. 


$$
\text { }
$$

(1)

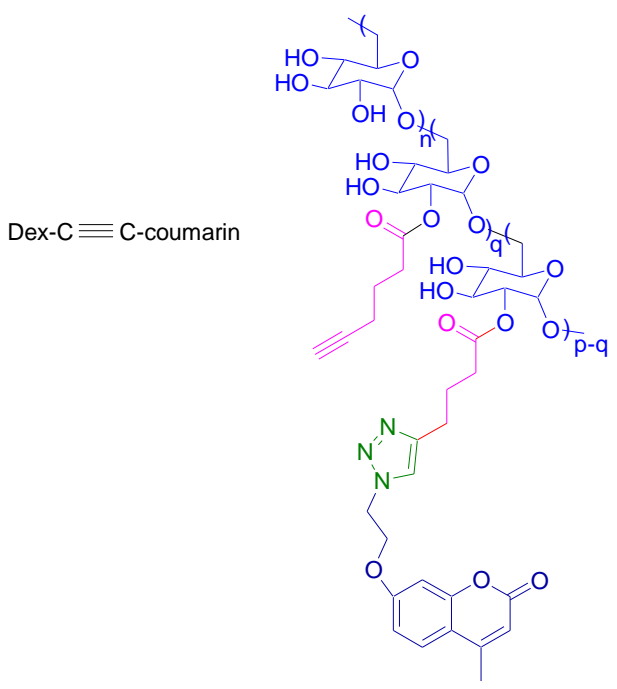

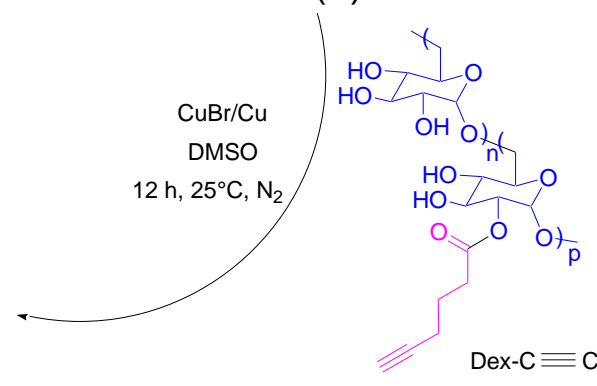

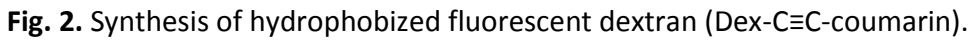

night. PLA batches were purchased from Aldrich $\left(\mathrm{PLA}^{\text {Aldrich }}, \overline{\mathrm{M}_{\mathrm{n}}}=\right.$ $27,000 \mathrm{~g} \mathrm{~mol}^{-1}$ and $Đ=1.9$ ) or donated by Natureplast (PLA Natureplast, $\overline{\mathrm{M}_{\mathrm{n}}}=31,000 \mathrm{~g} \mathrm{~mol}^{-1}$ and $\left.Ð=1.7\right)$. These PLA molar masses were determined by SEC-MALLS in THF. PVA was purchased from Aldrich $\left(\overline{\mathrm{M}_{\mathrm{n}}} \# 3,000 \mathrm{~g} \mathrm{~mol}^{-1}\right.$ and $23 \%$ acetate as estimated by ${ }^{1} \mathrm{H}$ NMR in DMSO- $\left.d_{6}\right)$. Glycidytrimethylammonium chloride, 1,2-epoxyoctane, tetrabutylammonium hydroxide 30-hydrate (TBAOH), 4methylumbelliferone (7-Hydroxy-4-methylcoumarin), 1,2dibromoethane, copper sulphate pentahydrate $\left(\mathrm{CuSO}_{4}, 5 \mathrm{H}_{2} \mathrm{O}\right)$,

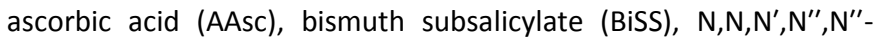
pentamethyldiethylenetriamine (PMDETA), ethylenediamine tetraacetic acid (EDTA), sodium dodecyl sulphate (SDS), tosyl chloride $(\mathrm{TsCl})$, triethylamine $\left(\mathrm{Et}_{3} \mathrm{~N}\right)$, trimethylamine hydrochloride, potassium carbonate $\left(\mathrm{K}_{2} \mathrm{CO}_{3}\right)$, magnesium sulphate $\left(\mathrm{MgSO}_{4}\right)$, sodium azide $\left(\mathrm{NaN}_{3}\right)$, copper and copper(I) bromide $(\mathrm{CuBr})$ were obtained from Sigma-Aldrich and used without any further purification. $\mathrm{CH}_{2} \mathrm{Cl}_{2}$, DMF, DMSO were dried and distilled with appropriate methods before use. Activated hex-5-ynoic acid was prepared according previous paper ${ }^{41}$. D, L-lactide was purchased from Alfa Aesar, recrystallized twice from fresh distilled toluene and dried under vacuum for a night. Benzyl alcohol (BzOH) was purchased from Aldrich, vacuum distilled over $\mathrm{CaH}_{2}$, then diluted with dry $\mathrm{CH}_{2} \mathrm{Cl}_{2}$. Culture medium was alpha-minimum essential medium ( $\alpha$-MEM) (purchased from Sigma) supplemented with $5 \%$ human platelet lysate, $1 \%$ antibiotics (penicillin G, streptomycin, amphotericin B, Fisher W3473M), $4 \mathrm{mM}$ glutamine and 2 IU heparin. Hydrophobized dextran (Dex- $C_{6}$, Fig. 1$)^{42}$ and alkynated dextran (Dex-C $\equiv C$, Fig. 1$)^{41}$ were obtained as previously described. In the following, the dextran derivatives will be called Dex- $X^{\%}$ or Dex $-X^{\%}-Y^{\%}$, where $X$ and $Y$ stand for the grafted group (for example, $\mathrm{C}_{6}$ or $\mathrm{C} \equiv \mathrm{C}$ ) and $\%$ the yield of substitution (i.e., the number of grafted ( $\mathrm{X}$ or $\mathrm{Y}$ ) groups per 100 glucopyranosic units). In the present study, Dex- $\mathrm{C}_{6}{ }^{14}$ and Dex-C $\equiv \mathrm{C}^{27}$ (see ${ }^{1} \mathrm{H}$ NMR spectra in Fig S1) were selected due to their convenient interfacial properties to decrease liq/liq interface and to stabilize solid PLA/water interface.

\section{Dex- ${ }_{6}-\mathrm{C} \equiv \mathrm{C}$ (Fig. 1)}

Dex- $\mathrm{C}_{6}{ }^{7}$, produced as previously reported ${ }^{42}$ was modified to introduce several alkyne groups ${ }^{41}$. Briefly, around $10.0 \mathrm{~g}$ of Dex $-\mathrm{C}_{6}{ }^{7}$ were dissolved in $100 \mathrm{~mL}$ of dry DMSO at $60^{\circ} \mathrm{C}$. 0.10 eq. of activated hex-5-ynoic acid per glucopyranosic unit were then added to the medium, which was left under stirring at $60^{\circ} \mathrm{C}$ for $48 \mathrm{~h}$. Crude product was precipitated twice in cold ethanol, then dried under vacuum at room temperature for one night. The yield of substitution in alkyne groups was estimated by ${ }^{1} \mathrm{H}$ NMR in DMSO$d_{6}$, according to equation 1 :

$\%$ of alkyne groups $=\frac{A_{b} / 2}{\left(A_{\mathrm{H} 1}+A_{\mathrm{OH}}\right) / 4} * 100 \quad$ (equation 1)

with $A_{b}$ the peak area of two protons $b$ (centred at $1.7 \mathrm{ppm}$ ), $A_{\mathrm{H} 1}$ the peak area of anomeric protons (from 4.6 to $4.7 \mathrm{ppm}$ ) and $A_{\mathrm{OH}}$ the total area peaks of the hydroxyl protons of the glucopyranosic unit $\left(\mathrm{OH}_{2}, \mathrm{OH}_{3}, \mathrm{OH}_{4}\right.$, between 4.4 and $\left.5.2 \mathrm{ppm}\right)$ (Fig. S1). As previously demonstrated, $\left(A_{1}+A_{O H}\right)$ corresponds globally to four protons per glucopyranosic unit, whatever the substitution yield ${ }^{43}$.

\section{Ammonium functionalized hydrophobized dextran (Dex- $\mathbf{N}^{+}-\mathrm{C}_{6}$, Fig.} 1)

In the first step, $5.0 \mathrm{~g}$ of dextran were dissolved in $50 \mathrm{~mL}$ of $\mathrm{NaOH}$ (1 $\mathrm{mol} / \mathrm{L}$ ) by stirring at $25^{\circ} \mathrm{C}$. $1.90 \mathrm{~mL}$ of glycidyltrimethylammonium chloride (1.27 $10^{-2} \mathrm{~mol} \mathrm{~L}^{-1}, 0.41$ eq. per glucopyranosic unit) were then added to the medium, and the reaction was left stirring at $25^{\circ} \mathrm{C}$ for 48 hours. Crude Dex- $\mathrm{N}^{+}$was precipitated in cold methanol, 
dialyzed against deionized water for $24 \mathrm{~h}$, then freeze-dried. The yield of substitution in ammonium groups was estimated equal to $11 \%$ by ${ }^{1} \mathrm{H}$ NMR in $\mathrm{D}_{2} \mathrm{O}$ according to equation 2 :

$\%$ of $\mathrm{N}^{+}=\frac{A_{D} / 9}{A_{H 1}} * 100$

(equation 2)

with $A_{D}$ the peak area of the methyl protons $D$ from the ammonium groups (3.3 ppm) and $A_{H 1}$ the peak area of anomeric protons (5.05 ppm) (Fig S2).

In the last step, $\mathrm{C}_{6}$ chains were partially grafted on residual hydroxide functions of Dex- $\mathrm{N}^{+}$according to the synthesis described earlier ${ }^{42}$. Briefly, $5.0 \mathrm{~g}$ of Dex $-\mathrm{N}^{+11}$ were dissolved in $45 \mathrm{~mL}$ of DMSO, then 0.40 eq of $\mathrm{TBAOH}$ and 0.31 eq of 1,2-epoxyoctane per glucopyranosic unit were added to the medium. The reaction was stirred at $25^{\circ} \mathrm{C}$ during $48 \mathrm{~h}$, then crude Dex- $\mathrm{N}^{+}-\mathrm{C}_{6}$ product was precipitated in cold methanol and freeze-dried for one night. The yield of substitution in $\mathrm{C}_{6}$ was estimated by ${ }^{1} \mathrm{H}$ NMR in $\mathrm{D}_{2} \mathrm{O}$ according to equation 3 :

$\%$ of $\mathrm{C}_{6}=\frac{\mathrm{A}_{\mathrm{H} 14} / 3}{\mathrm{~A}_{\mathrm{H} 1}} * 100$ (equation 3)

with $\mathrm{A}_{\mathrm{H} 14}$ the peak area of the 3 methyl protons (from 0.9 to 1.1 ppm, Fig. S2).

\section{Ammonium functionalized alkynated dextran (Dex- $\mathrm{N}^{+}-\mathrm{C} \equiv \mathrm{C}$ )}

Dex $-\mathrm{N}^{+}-\mathrm{C} \equiv \mathrm{C}$ was obtained from Dex- $\mathrm{N}^{+11}$ (see above) and alkyne groups were grafted in the last step (Fig. 1C), according previously described procedure ${ }^{41}$. Briefly, $5.0 \mathrm{~g}$ of Dex- $\mathrm{N}^{+11}$ were dissolved in $50 \mathrm{~mL}$ of DMSO by stirring at $60^{\circ} \mathrm{C} .0 .25$ eq. of activated hex-5-ynoic acid per glucopyranosic unit were then added to the medium, which was left under stirring at $60^{\circ} \mathrm{C}$ for $48 \mathrm{~h}$. Crude Dex- $\mathrm{N}^{+}-\mathrm{C} \equiv \mathrm{C}$ product was precipitated in cold ethanol, dialyzed against deionized water for $24 \mathrm{~h}$, then freeze-dried. The yield of substitution in alkyne groups was estimated by ${ }^{1} \mathrm{H}$ NMR in $\mathrm{D}_{2} \mathrm{O}$ according to equation 4 :

$\%$ of alkyne groups $=\frac{A_{b} / 2}{A_{H}} * 100$

(equation 4)

with $A_{b}$ the peak area of two protons $b$ (from 1.8 to 2.0 ppm, Fig S2).

\section{Alkynated fluorescent Dex-C $=$ C-Coumarin (Fig. 2)}

Firstly, $5.0 \mathrm{~g}$ of 4-methylumbelliferone $\left(2.83810^{-2} \mathrm{~mol}\right)$ were dissolved in $50 \mathrm{~mL}$ of dry DMF at $60^{\circ} \mathrm{C}$, then 2.0 eq. of $\mathrm{K}_{2} \mathrm{CO}_{3}(7.845$ $\left.\mathrm{g}, 5.67610^{-2} \mathrm{~mol}\right)$ were added. The medium was evacuated and filled by nitrogen three times and left under nitrogen. Next, 10.0 eq. of 1,2-dibromoethane $\left(24,45 \mathrm{~mL}, 2.83810^{-1} \mathrm{~mol}\right)$ were introduced in the medium and the reaction was left under stirring and nitrogen at $60^{\circ} \mathrm{C}$ for 3 hours. The reaction was carried out away from light. Afterward, $100 \mathrm{~mL}$ of $\mathrm{CH}_{2} \mathrm{Cl}_{2}$ and $100 \mathrm{~mL}$ of water were added to the medium. The aqueous layer was extracted three times with 100 $\mathrm{mL}$ of $\mathrm{CH}_{2} \mathrm{Cl}_{2}$. Organic layers were combined, washed five times with $100 \mathrm{~mL}$ of water, dried over $\mathrm{MgSO}_{4}$ and evaporated under reduced pressure at $40^{\circ} \mathrm{C}$. The product (1) was finally dried under vacuum for one night and obtained as a white powder (Fig. S3).

Secondly, $2.0 \mathrm{~g}$ of (1) $\left(7.06410^{-3} \mathrm{~mol}\right)$ were dissolved in $30 \mathrm{~mL}$ of dry DMSO by stirring at $25^{\circ} \mathrm{C} .1 .1$ eq. of $\mathrm{NaN}_{3}\left(0.505 \mathrm{~g}, 7.77110^{-3} \mathrm{~mol}\right.$ ) were then added to the medium and the reaction was left under stirring at $25^{\circ} \mathrm{C}$ for 48 hours in the dark. Next, $100 \mathrm{~mL}$ of $\mathrm{CH}_{2} \mathrm{Cl}_{2}$ and $100 \mathrm{~mL}$ of water were poured into the medium. The aqueous layer was extracted twice with $100 \mathrm{~mL}$ of $\mathrm{CH}_{2} \mathrm{Cl}_{2}$. Organic layers were combined, washed twice with $100 \mathrm{~mL}$ of water, dried over $\mathrm{MgSO}_{4}$ and evaporated under reduced pressure at $40^{\circ} \mathrm{C}$. The product (2) was finally dried under vacuum for one night and obtained as a white powder (Fig. S3).

Finally, $4.0 \mathrm{~g}$ of Dex-C $\equiv \mathrm{C}^{25}$ were dissolved in $40 \mathrm{~mL}$ of dry DMSO by stirring at $25^{\circ} \mathrm{C} .0 .02$ eq. of (2) per glucopyranosic unit $(0.106 \mathrm{~g}$, $4.30910^{-4} \mathrm{~mol}$ ) were introduced, and the medium was degassed under stirring and nitrogen flow. Next 2.0 eq. of $\mathrm{CuBr}$ per mole of (2) $\left(0.124 \mathrm{~g}, 8.61810^{-4} \mathrm{~mol}\right)$ and 2.1eq. of $\mathrm{Cu}$ per mole of (2) $(57.5$ $\mathrm{mg}, 9.05010^{-4} \mathrm{~mol}$ ) were introduced. The medium was evacuated, filled with nitrogen three times, and left under nitrogen and stirring at $25^{\circ} \mathrm{C}$ for one night to carry out CuAAC between (2) and Dex$\mathrm{C} \equiv \mathrm{C}^{25}$. The crude product Dex-C $\equiv \mathrm{C}$-coumarin was precipitated in $400 \mathrm{~mL}$ of cold ethanol containing $4 \mathrm{~mL}$ of PMDETA to help the copper removal. Next, crude product was suspended in $400 \mathrm{~mL}$ of ethanol by vigorous stirring at room temperature for one night, then dialyzed against EDTA aqueous solution (\# 5 eq. per $\mathrm{Cu}$ ) during 4 days and against milli- $Q$ water for 3 days. Finally, Dex- $\mathrm{C} \equiv \mathrm{C}-$ coumarin was freeze-dried for 48 hours and the yield of substitution in coumarin was estimated by ${ }^{1} \mathrm{H}$ NMR in DMSO- $d_{6}$ according to equation 5 :

$\%$ of coumarin group $=\frac{A_{\mathrm{H} 14}}{\left(A_{\mathrm{H} 1}+A_{\mathrm{OH}}\right) / 4} * 100$

(equation 5)

with $A_{H 14}$ the peak area of the triazole ring proton (7.95 ppm, Fig. S3)

$\omega$-azide PLA (PLA-N $\left.{ }_{3}\right)$

PLA- $\mathrm{N}_{3}$ was obtained according to a three-step strategy (Fig. 3). In the first step, $20.0 \mathrm{~g}$ of $\mathrm{D}, \mathrm{L}$-lactide $(0.139 \mathrm{~mol})$ were weighed into a $100 \mathrm{~mL}$ round-bottomed flask previously flame dried. Then, in a glovebox, $0.93 \mathrm{~mL}$ of $\mathrm{BzOH}$ solution in $\mathrm{CH}_{2} \mathrm{Cl}_{2}$ (6.641 $10^{-4} \mathrm{M}, 6.16510^{-4} \mathrm{~mol}$ ) were added to the medium, followed by $7.0 \mathrm{mg}$ of BiSS $\left(1.93310^{-5} \mathrm{~mol}\right)$. The catalyst to initiator molar ratio was set to 0.03 . The medium was evacuated to evaporate $\mathrm{CH}_{2} \mathrm{Cl}_{2}$, filled by nitrogen, then placed into an oil bath at $150^{\circ} \mathrm{C}$ and the reaction was left for 4 hours. After addition of a catalytic amount of acidified ethanol to stop the polymerization, conversion was finally estimated to be $61 \%$ from ${ }^{1} \mathrm{H}$ NMR spectrum in $\mathrm{CDCl}_{3}$ of crude product (Fig. $\mathrm{S} 4)^{44}$. The reaction medium was dissolved in THF then precipitated in cold ethanol. $\overline{\mathrm{M}_{\mathrm{n}}}$ was evaluated to be $18,200 \mathrm{~g}$ $\mathrm{mol}^{-1}$ from ${ }^{1} \mathrm{H}$ NMR spectrum of purified product in $\mathrm{CDCl}_{3}$ using $\overline{\mathrm{M}_{\mathrm{n}}}=(72 \times \mathrm{B}) /(\mathrm{C} / 5)+108$, where $\mathrm{B}$ and $\mathrm{C}$ are the areas 
of PLA methyne protons (5.15 ppm) and of aromatic protons from initiator group (7.35 ppm), respectively (Fig. S4). 108 and 72 are the molecular weights of benzyl alcohol and PLA repetition unit, respectively.<smiles>CC1OC(=O)C(C)OC1=O</smiles>

D, L-lactide<smiles>CC(C)OC(C)C(=O)C(C)OC(C)C(=O)C(C)OCc1ccccc1</smiles>

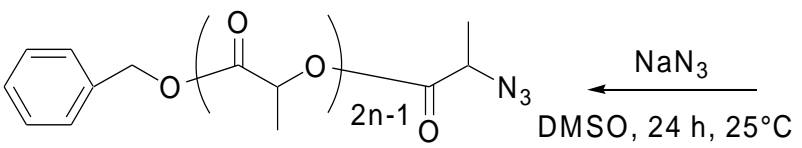<smiles>CC(OC(C)(C)C(=O)C(C)OS(=O)(=O)c1ccc(I)cc1)C(=O)C(C)(C)OCc1ccccc1</smiles>

Fig. 3. Synthesis of azido end-functionalized PLA (PLA-N $\left.\mathrm{N}_{3}\right)$.

In the second step, terminal hydroxyl group was activated by reaction with $\mathrm{TsCl}$. Briefly, 6.0g of PLA (3.296 $10^{-4} \mathrm{~mol}$ ) were dissolved in $60 \mathrm{~mL}$ of $\mathrm{CH}_{2} \mathrm{Cl}_{2}$, then 3 eq. of $\mathrm{TsCl}$ per $\mathrm{OH}$ function $\left(9.88810^{-4} \mathrm{~mol}\right), 0.1$ eq. of $\mathrm{NMe}_{3}, \mathrm{HCl}\left(3.29610^{-5} \mathrm{~mol}\right)$ and 6 eq. of $\mathrm{NEt}_{3}\left(1.97810^{-3} \mathrm{~mol}\right)$ were added into the medium, and the reaction was left under stirring and nitrogen at room temperature for a night. Tosylated PLA was purified as described above, then characterized by ${ }^{1} \mathrm{H}$ NMR in $\mathrm{CDCl}_{3}$ (Fig. S4). Finally, tosylated PLA was substituted using 5 eq. of sodium azide per tosyl group in DMSO $(10 \mathrm{~mL} / \mathrm{g}$ of tosylated PLA), for one day at $25^{\circ} \mathrm{C}$ (third step). PLA- $\mathrm{N}_{3}$ was obtained after precipitation from cold ethanol (Fig. S4).

\section{Formulation and characterization of nanoparticles (NPs)}

Non-clicked NPs were obtained via an emulsion/evaporation process, according to previously described procedure ${ }^{13,37} .50$ mg of PLA (commercial PLAs or PLA- $\mathrm{N}_{3}$ ) were dissolved in $2 \mathrm{~mL}$ of $\mathrm{CH}_{2} \mathrm{Cl}_{2}$, then poured into $20 \mathrm{~mL}$ of aqueous solution $\left(\mathrm{CH}_{2} \mathrm{Cl}_{2^{-}}\right.$ saturated Milli-Q water) of Dex- $\mathrm{C}_{6}{ }^{7}-\mathrm{C} \equiv \mathrm{C}^{10}$ (or PVA) at $5 \mathrm{~g} \mathrm{~L}^{-1}$. $0.5 \mathrm{M} \mathrm{NaCl}$ aqueous phase was used instead of Milli-Q water in the case of Dex- $\mathrm{N}^{+}-\mathrm{C}_{6}$ surfactant. The mixture was preemulsified using vortex at 2,500 rpm for 1 minute and emulsified by sonication for 2 minutes using a Vibracell $600 \mathrm{~W}$ sonde (Bioblock Scientific, pulsed mode, $\mathrm{P}=50 \%$, ice bath). After sonication, $\mathrm{CH}_{2} \mathrm{Cl}_{2}$ was evaporated at $40^{\circ} \mathrm{C}$ for 2 hours under stirring. NPs suspension was centrifuged ( $30 \mathrm{~min} ; 15,000$ $\mathrm{rpm}$ ) to remove the non-adsorbed surfactant, then redispersed in water using Branson 2510 ultrasounds bath. These washing steps were repeated twice, before particle size analysis.

Formulation of the clicked NPs was performed as described above for non-clicked NPs. However, an in situ interfacial CUAAC was carried out according to previous paper ${ }^{37}$. Briefly, before pouring the PLA- $\mathrm{N}_{3}$ organic phase into the aqueous one, $0.5 \mathrm{~mL}$ of ascorbic acid (1.95 M aqueous solution; 10 eq. per $\mathrm{CuSO}_{4}$ ) were added into the aqueous phase. The interfacial click reaction was initiated by adding 5 eq. of $\mathrm{CuSO}_{4}$ in water (100 $\mu \mathrm{L}, 0.96 \mathrm{M}$ aqueous solution) per alkyne function of Dex$\mathrm{C}_{6}{ }^{7}-\mathrm{C} \equiv \mathrm{C}^{10}$ just before sonication. To eliminate residual copper, resulting NPs suspension was stirred with EDTA ( $\sim 5 \mathrm{eq} / \mathrm{Cu})$ at room temperature over one night, then centrifuged and washed as described above.

After formulation, NPs were freeze-dried and dissolved in DMSO- $d_{6}$ to quantify the dextran surface coverage $\left(\Gamma_{\text {Dex }}\right)$ using ${ }^{1} \mathrm{H}$ NMR spectrum according to equation 6 :

$\Gamma_{\text {Dex }}=\frac{\mathrm{A}_{\mathrm{H} 1} * \mathrm{M}_{\mathrm{Dex}}}{\mathrm{A}_{\mathrm{CHPLA}} * \mathrm{M}_{\mathrm{PLA}} * \mathrm{~S}_{\mathrm{p}}}$

(Equation 6)

with $A_{\text {CHPLA }}$ the peak area of the methine proton of PLA centred at $5.15 \mathrm{ppm}$ and $\mathrm{A}_{\mathrm{H} 1}$ the peak area of anomeric protons of dextran (4.6-4.7 ppm). $M_{\text {Dex }}$ and $M_{P L A}$ are the molar masses of dextran and PLA repeating unit, respectively $\left(\mathrm{M}_{\text {Dex }}=162 \mathrm{~g} / \mathrm{mol}\right.$ and $\mathrm{M}_{\mathrm{PLA}}=$ $72 \mathrm{~g} / \mathrm{mol}) . S_{p}$ is the specific surface area $\left(\mathrm{m}^{2} / \mathrm{g}\right)$ determined by laser granulometry (see below). The PVA surface coverage $\left(\Gamma_{\mathrm{PVA}}\right)$ was quantified as above, but using equation 7 :

$\Gamma_{\mathrm{PVA}}=\frac{\frac{\mathrm{A}_{\mathrm{CH} 3}-\mathrm{PVA}}{3 * \%_{\mathrm{CH}} 3} * \mathrm{M}_{\mathrm{PVA}}}{\mathrm{A}_{\mathrm{CHPLA}} * \mathrm{M}_{\mathrm{PLA}} * \mathrm{~S}_{\mathrm{p}}}$

(Equation 7)

with $\mathrm{A}_{\mathrm{CH} 3-\mathrm{PVA}}$ the peak area of the acetate protons of PVA (centred at $1.96 \mathrm{ppm}$ ), $\%_{\mathrm{CH} 3}$ the number of acetate groups per 100 units of PVA and $\mathrm{M}_{\mathrm{PVA}}$ the molar mass of PVA monomer unit taking into account the $\%{ }_{\mathrm{CH} 3}$.

\section{Formulation and characterization of microcarriers (MCs)}

All MCs (clicked and non-clicked) have been obtained via an emulsion/evaporation process using a $250 \mathrm{~mL}$ glass reactor immersed in an oil bath, and a mechanical stirrer with a 4 blades propeller (Fig. 4). $200 \mathrm{mg}$ of PLA (commercial PLAs or PLA- $\mathrm{N}_{3}$ ) were dissolved in $4 \mathrm{~mL}$ of $\mathrm{CH}_{2} \mathrm{Cl}_{2}$. Meanwhile, $200 \mathrm{mg}$ of dextran derivative were dissolved in $40 \mathrm{~mL}$ of water $\left(\mathrm{CH}_{2} \mathrm{Cl}_{2}\right.$-saturated). 0.5 
$\mathrm{M} \mathrm{NaCl}$ aqueous phase was used instead of water in the case of ammonium-functionalized derivatives (Dex- $\mathrm{N}^{+}-\mathrm{C}_{6}$, Dex- $\mathrm{N}^{+}-\mathrm{C} \equiv \mathrm{C}$ ). The aqueous phase was then poured into the reactor and left under stirring $(\approx 170 \mathrm{rpm})$ at $40^{\circ} \mathrm{C}$ for at least 30 minutes. Next, the stirring speed was increased to the required value, while the organic phase was added dropwise using a syringe pump $(130 \mathrm{~mL} / \mathrm{h})$. The mixture was left under stirring at $40^{\circ} \mathrm{C}$ for 4 hours to evaporate $\mathrm{CH}_{2} \mathrm{Cl}_{2}$ before filtration. Recovered MCs were washed by $3 * 20 \mathrm{~mL}$ of milliQ water, then dispersed again in water for particle size analysis before freeze-drying.

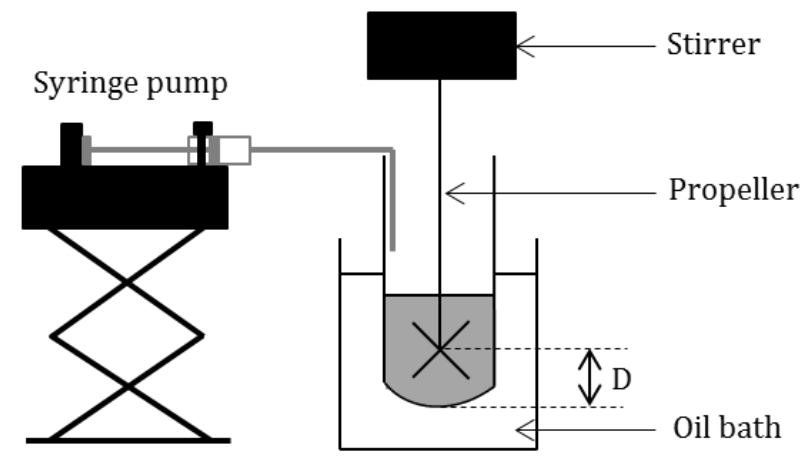

Fig. 4: Apparatus used for the preparation of MCs. D is defined as the distance between the propeller's blades and the bottom of the reactor.

In some experiments, an in situ interfacial CuAAC was carried out according to previous paper ${ }^{37}$. Briefly, before pouring the PLA- $\mathrm{N}_{3}$ organic phase into the aqueous one, ascorbic acid (10 eq. per $\mathrm{CuSO}_{4}$ ) was added into the aqueous phase. After final addition of the organic phase, the interfacial click reaction was initiated by adding 5 eq. of $\mathrm{CuSO}_{4}$ per alkyne function of dextran derivatives. To eliminate residual copper, resulting MCs suspension was stirred with EDTA (see above).

\section{Colloidal stability of NPs}

The colloidal stability of NPs (MCs) dispersions was studied in the presence of SDS (or culture medium) by redispersion NPs (MCs) in $10 \mathrm{~mL}$ of SDS $1 \mathrm{wt} \%$ (or culture medium), then left under stirring for $24 \mathrm{~h}$ at room temperature ( 8 days, $37^{\circ} \mathrm{C}$ for culture medium). NPs were centrifuged, washed again and freeze-dried as described before, while MCs were filtrated, washed by $3 * 20 \mathrm{~mL}$ of milli- $\mathrm{Q}$ water, then freeze-dried. ${ }^{1} \mathrm{H}$ NMR analysis of NPs dissolved in DMSO- $d_{6}$ was performed before and after treatment by SDS (or by culture medium) to quantify the percentage of desorbed dextran using equation 8 . In case of PVA surface coverage, $A_{H 1}$ was replaced by $\left(\mathrm{A}_{\mathrm{CH} 3-\mathrm{PVA}} / 3\right)$ in equation 8 .

$\%$ of Dex desorbed $=\left[1-\frac{\left(\mathbf{A}_{\mathrm{H} 1} / \mathbf{A}_{\mathrm{CHPLA}}\right)_{\text {after }}}{\left(\mathbf{A}_{\mathbf{H} 1} / \mathbf{A}_{\mathrm{CHPLA}}\right)_{\text {before }}}\right] \times 100 \quad$ (Equation 8)

\section{Characterization techniques}

${ }^{1} \mathrm{H}$ NMR spectra were recorded on a Bruker Avance 300 apparatus (300.13 MHz, $25^{\circ} \mathrm{C}$ ) in DMSO- $d_{6}, \mathrm{D}_{2} \mathrm{O}$ or $\mathrm{CDCl}_{3}$.

Steric Exclusion Chromatography (SEC) in THF was performed at $40^{\circ} \mathrm{C}$ with a Multi Angle Laser Light Scattering detector (MALLS Mini Dawn Treos, Wyatt), a differential refractometer detector (OPTILab rex, Wyatt), a pump (Waters 515, elution rate of $1 \mathrm{~mL} . \mathrm{min}$ ${ }^{1}$ ), a degasser $A F$ (waters in-line) and 3 PLgel columns ( $300 \mathrm{~nm} * 7.5$ $\mathrm{nm}, 10_{5} \AA, 10_{3} \AA, 100 \AA$ ). Refractive index increment of PLA in THF (dn/dc) was equal to $0.054 \mathrm{~mL} / \mathrm{g}$. SEC in water (0.1 $\mathrm{M} \mathrm{NaNO}_{3}, 6.15$ $10^{-3} \mathrm{M} \mathrm{NaN}_{3}$ ) was performed at room temperature using a Waters HPLC pump (Waters 410) equipped with a DG-1310 degasser, a serial set of SB-806-HQ, SB-805-HQ, SB-804-HQ OHPack columns, and SB-OH Pack guard column (Shodex). Elution ( $0.7 \mathrm{~mL} \mathrm{~min}^{-1}$ ) was dually monitored by multiangle laser light scattering (MALLS) and differential refractometry (Waters 410$)$. Solutions (10 g/L) were prepared by dissolution of samples in eluent under vigorous stirring for $24 \mathrm{~h}$. The solutions were filtrated using a HA Millex syringe filter $(0.2 \mu \mathrm{m})$ right before injection. $\mathrm{dn} / \mathrm{dc}$ of dextran in aqueous phase was equal to $0.146 \mathrm{~mL} / \mathrm{g}$.

NPs and MCs size distributions were determined by using Laser light diffraction (Mastersizer 2000 Malvern Instruments) after dispersion in Milli-Q water. Each measurement was performed three times. The broadness of diameter distributions was estimated by calculating the Span according to equation 9 , where $D(0.1), D(0.5)$ and $D(0.9)$ were the diameters at 10,50 and $90 \%$ of the NPs volume distribution, respectively. Generally speaking, the broader the distribution was (monomodal or multimodal), the higher the Span was. In the case of monomodal and narrow size distributions, the Span values were lower than 2. To evaluate specific surface area (Sp), density of PLA was given to be $1.25 \mathrm{~g} / \mathrm{mL}$, whatever the PLA batch.

Span $=\frac{\mathrm{D}(0.9)-\mathrm{D}(0.1)}{\mathrm{D}(0.5)}$

(Equation 9)

The scanning electron microscope (SEM) investigations were performed on JEOL Scanning Electron Microscope JSM-6490 $\mathrm{LV}$, acceleration voltage of $0.3-30 \mathrm{kV}$, pressure of 1-270 Pa.

Fluorescent MCs were observed using a confocal microscope (Fluoview FV-10i, Olympus). Excitation wavelength was selected at $352 \mathrm{~nm}$ and fluorescence signal was collected at $455 \mathrm{~nm}$. Magnitude was 45. The images were processed with Image J image-processing software (http://imagej.nih.gov).

\section{Results and discussion}

\section{Dextran-based surfactants}

In the present paper, several new dextran-based amphiphilic polymers were produced to be used as interfacial stabilizers. Along their syntheses, SEC traces confirmed the non-degrading character of each modification step (not shown). As the reactivity order of the hydroxyl groups in dextran was found to be $\mathrm{OH}^{2}>\mathrm{OH}^{4}>\mathrm{OH}^{3}{ }^{43}$, the modified $\mathrm{OH}$ were drawn to be $\mathrm{OH}^{2}$ on figures. According to Fig. 1, several alkyne groups were introduced onto Dex $-\mathrm{C}_{6}{ }^{7}$ (7 hydrophobic 
$\mathrm{C}_{6}$ chains per 100 glucopyranosic units) through a partial esterification with an activated 5-hexynoic acid ${ }^{41} .{ }^{1} \mathrm{H}$ NMR spectrum of purified Dex- $\mathrm{C}_{6}-\mathrm{C} \equiv \mathrm{C}$ (Fig S1) shows a peak at 2.75 ppm, corresponding to alkyne proton (d), and 3 peaks ( $a, b$ and $c$ ) from 1.6 to $2.4 \mathrm{ppm}$, characteristic of methylene protons from the alkyl spacer. According to equation 1, the yield of substitution in alkyne groups was evaluated to $10 \%$ (10 pending alkynyl groups per 100 glucopyranosic units). Considering the equivalence of the activated 5-hexynoic acid, a quantitative reaction was achieved.

Two ammonium-functionalized dextran-based surfactants (Fig. 1) were produced to in fine formulate MCs with a positive shell, as found for Cytodex-1 for instance. Firstly, dextran was reacted with glycidyltrimethylammonium chloride in a basic medium to link ammonium groups via an ether function. As shown on ${ }^{1} \mathrm{H}$ NMR spectrum of purified Dex- $\mathrm{N}^{+}$(Fig. S2), the methyl protons (D) peak can be observed at $3.3 \mathrm{ppm}$, while the peaks ( $a, b$ and $c)$ from methylene and methyne protons overlap with those of glucosidic protons (3.4-4.2 ppm). The yield of substitution in ammonium groups (11\%) was quantified according to equation 2 . Such Dex- $\mathrm{N}^{+11}$ was then converted to Dex- $\mathrm{N}^{+}-\mathrm{C}_{6}$ carrying several $\mathrm{C}_{6}$ chains or to Dex $-\mathrm{N}^{+}-\mathrm{C} \equiv \mathrm{C}$ by reaction with the activated 5 -hexynoic acid. As shown on ${ }^{1} \mathrm{H}$ NMR spectrum of Dex $-\mathrm{N}^{+}-\mathrm{C}_{6}$ (Fig. S2), peaks corresponding to grafted $\mathrm{C}_{6}$ chains protons are present at $1 \mathrm{ppm}$ (methyl protons (14)) and between 1.2 and $1.8 \mathrm{ppm}$ (methylene protons (9-13)), while peaks characteristic from protons $(7,8)$ overlap with the glucosidic protons ones. The yield of substitution of $\mathrm{C}_{6}$ chains was evaluated equal to $14 \%$ according to equation 3 . As shown in ${ }^{1} \mathrm{H} N M R$ spectrum of Dex- $\mathrm{N}^{+}-\mathrm{C} \equiv \mathrm{C}$ (Fig S2), alkynyl proton (d) peak is observed at $2.65 \mathrm{ppm}$ when peaks characteristic of methylene protons $(a, b$ and $c)$ from the alkyl spacer, are observed between 1.6 and $2.5 \mathrm{ppm}$. According to equation 4, the yield of substitution by alkynyl groups was evaluated equal to $24 \%$.

\section{Alkynated Fluorescent Dextran Dex-C $\equiv$ C-Coumarin}

4-methylumbelliferone (7-hydroxy-4-methylcoumarin) was modified by reaction with 1,2-dibromoethane to yield the bromo-functionalized derivative (1) (Fig. 2). The corresponding ${ }^{1} \mathrm{H}$ NMR spectrum (Fig. S3) shows peaks attributed to aromatic protons of 4-methylumbelliferone (A at $6.2 \mathrm{ppm}, \mathrm{C}$ centred at $7.7 \mathrm{ppm}$ and $(\mathrm{D}+\mathrm{E})$ at around $7 \mathrm{ppm})$ and to the methyl protons (B) centred at $2.4 \mathrm{ppm}$. This spectrum also displays peaks corresponding to the methylene protons from the spacer ( $F$ at $4.45 \mathrm{ppm}$ and $G$ at $3.85 \mathrm{ppm}$ ). After the substitution of bromide with azido function, the ${ }^{1} \mathrm{H} N M R$ spectrum of (2) (Fig. S3) reveals a shift of both peaks of protons $F$ (from 4.45 to $4.35 \mathrm{pm}$ ) and $\mathrm{G}$ (from 3.85 to 3.70 ppm). After linking (2) onto Dex-C $\equiv C^{25}$ by CuAAC click chemistry, the ${ }^{1} \mathrm{H}$ NMR spectrum of Dex- $\mathrm{C} \equiv \mathrm{C}$-Coumarin exhibits peaks characteristic from both the dextran and coumarin parts. Moreover, one can see the triazole proton peak centered at $8 \mathrm{ppm}$, which proves the efficiency of the CuAAC, while peak of protons $\mathrm{G}_{1}$ overlaps with the glucosidic protons peaks (3-4 ppm). A small peak centred at $4.1 \mathrm{ppm}$ characteristic of protons $F_{2}$ was observed. The yield of substitution in coumarin groups was estimated equal to $1.5 \%$ according to equation 5 .

\section{PLA- $\mathbf{N}_{3}$}

While alkyne end-chain functionalized PLA ${ }^{13,45}$ have already been reported, investigation on azido end-chain functionalized PLA (PLA$\mathrm{N}_{3}$ ) are scarce. To the best of our knowledge, only two papers described PLA- $\mathrm{N}_{3}$ synthesis, while a total azido-functionalization of the PLA end-chains was not observed. Isono et al. ${ }^{46}$ reported on the use of 6-azido-1-hexanol as initiator to produce PLA- $\mathrm{N}_{3}$, while modification of the end-hydroxyl function of PLA chains with 4azidobenzoic acid was reported by Sugai et al. ${ }^{47}$. In the present paper, we synthesized PLA- $\mathrm{N}_{3}$ via a three-step strategy (Fig. 3). Our objective was not to obtain a total azido-functionalization of the PLA chains. Indeed, this PLA-N $\mathrm{N}_{3}$ will be used to formulate NPs and MCs and the use of a mixture of PLA- $\mathrm{N}_{3}$ and PLA-OH is sufficient to obtain the expected clicked objects, as already reported ${ }^{13}$.

In the first step, PLA was produced by controlled bulk Ring Opening Polymerization (ROP) of D,L-lactide using benzyl alcohol as initiator and bismuth subsalicylate (BiSS) as catalyst ${ }^{44}$. BiSS, which is an antiulcer and antigastritis drug commonly marketed in oral medications, was selected here as a less toxic metallic catalyst than tin(II) 2-ethylhexanoate (the most widely used catalyst to promote cyclic esters ROP) since the cytotoxicity of this latter is still on debate $^{48,49}$. ROP was carried out at $150^{\circ} \mathrm{C}$ for 4 hours and $61 \%$ conversion was calculated from ${ }^{1} \mathrm{H}$ NMR spectrum in $\mathrm{CDCl}_{3}$ of crude product (Fig. S4). Theoretical $\overline{\mathrm{M}_{\mathrm{n}}}=19,800 \mathrm{~g} \mathrm{~mol}^{-1}$ was estimated in agreement with those obtained from ${ }^{1} \mathrm{H}$ NMR spectrum of purified product $\left(\overline{\mathrm{M}}_{\mathrm{n}}, \mathrm{NMR}=17,300 \mathrm{~g} \mathrm{~mol}^{-1}\right)$ and from SEC $\left(\overline{\mathrm{M}_{\mathrm{n}}, \mathrm{SEC}}=\right.$ $\left.18,400 \mathrm{~g} \mathrm{~mol}^{-1}, \mathrm{D}=1.2\right)$.

In the second step, terminal $\mathrm{OH}$ was substituted by tosylate group. ${ }^{1} \mathrm{H}$ NMR spectrum in $\mathrm{CDCl}_{3}$ of tosylated PLA (Fig. S4) shows peaks characteristic of tosylate, such as the aromatic protons at 7.15 and $7.75 \mathrm{ppm}$ and the methyl protons at $2.35 \mathrm{ppm}$. Comparison of the peak areas of aromatic protons from initiator and tosylate groups indicates a conversion of $45 \%$. Substitution of the tosylate group with azide function leads to the total disappearance of the previous peak from tosylate group, indicating that all tosylate groups are substituted by azide function.

As described above, this partial modified PLA- $\mathrm{N}_{3}$ will be used in the following to produce clicked particles (NPs and MCs), even if the modification was not quantitative. It should be noted that during all these modifications, SEC analysis did not reveal any significant degradation of the PLA chains.

\section{NPs formulation}

The second part of this work deals with a quantitative study of the NPs polysaccharidic shell stability in presence of competitive surfactant as Sodium Dodecyl Sulfate (SDS, anionic surfactant), 
which is known able to desorb various types of polymeric layers. Shell stability will also be investigated in the culture medium in order to check this stability in such a medium. The NPs we used exhibit similar chemistry than the MCs described below. More precisely, several kinds of PLA-based NPs were formulated by an emulsion/organic solvent evaporation (E/E) process already described $^{13,15}$, then their shell stability was studied. Firstly, various
PLA batches were evaluated: commercial PLA-based and PLA- $\mathrm{N}_{3-}$ based NPs. Secondly, we varied the chemical nature of the shell using either PVA or dextran derivatives (Table 1). Thirdly, in case of alkynated dextran derivatives (Dex- $\mathrm{C} \equiv \mathrm{C}^{27}$ and Dex $-\mathrm{C}_{6}{ }^{7}-\mathrm{C} \equiv \mathrm{C}^{10}$ ), the polysaccharidic shell was either physically adsorbed onto the PLA core (non-clicked

Table 1: Characteristics of NPs and shell stability towards SDS or culture medium.

\begin{tabular}{|c|c|c|c|c|c|c|c|c|c|c|c|}
\hline Entry & Core & Shell & Click & $\begin{array}{c}\mathrm{d}(0.1) \\
\mathrm{nm}\end{array}$ & $\begin{array}{c}\mathrm{d}(0.5) \\
\mathrm{nm}\end{array}$ & $\begin{array}{c}\mathrm{d}(0.9) \\
\mathrm{nm}\end{array}$ & Span & $\begin{array}{c}\Gamma_{\text {PVA or }} \Gamma_{\text {Dex }} \\
\text { before SDS } \\
\left(\mathrm{mg} / \mathrm{m}^{2}\right) \text { a) }\end{array}$ & $\begin{array}{c}\Gamma_{\text {PVA or }} \Gamma_{\text {Dex }} \\
\text { after SDS } \\
\left(\mathrm{mg} / \mathrm{m}^{2}\right)^{\text {a) }}\end{array}$ & $\begin{array}{c}\text { \% of Dex } \\
\text { (PVA) } \\
\text { desorbed } \\
\text { by SDS }^{\text {b) }}\end{array}$ & $\begin{array}{l}\text { \% of Dex } \\
\text { (PVA) } \\
\text { desorbed } \\
\text { by culture } \\
\text { medium }^{\text {b) }}\end{array}$ \\
\hline 1 & PLA $A^{\text {Aldrich }}$ & PVA & NO & 119 & 179 & 260 & 0.7 & 3.3 & 0 & 100 & - \\
\hline 2 & PLA ${ }^{\text {Natureplast }}$ & Dex- $C_{6}{ }^{14}$ & NO & 113 & 150 & 189 & 0,5 & 4.4 & 0.3 & 93 & - \\
\hline 3 & PLA ${ }^{\text {Natureplast }}$ & Dex $-C \equiv C^{27}$ & NO & 73 & 142 & 261 & 1,3 & 2.1 & 0. & 85 & - \\
\hline $4^{c)}$ & $\mathrm{PLA} \mathrm{N}_{3}$ & Dex $-C \equiv C^{27}$ & YES & 133 & 208 & 493 & 1.7 & 4.3 & 3.4 & 21 & - \\
\hline 5 & $\mathrm{PLA}^{\text {Aldrich }}$ & $D e x-C_{6}{ }^{7}-C \equiv C^{10}$ & NO & 68 & 120 & 204 & 1.1 & 2.2 & 0 & 100 & 100 \\
\hline 6 & $\mathrm{PLA} \mathrm{N}_{3}$ & $D e x-C_{6}{ }^{7}-C \equiv C^{10}$ & NO & 82 & 149 & 244 & 1.1 & 4.0 & 0 & 100 & \\
\hline $7^{c)}$ & $\mathrm{PLA} \mathrm{N}_{3}$ & Dex $-C_{6}{ }^{7}-C=C^{10}$ & YES & 121 & 158 & 197 & 0.48 & 6.2 & 3.2 & 48 & 78 \\
\hline 8 & PLA ${ }^{\text {Natureplast }}$ & Dex- $\mathrm{N}^{+11}-\mathrm{C}_{6}{ }^{14}$ & NO & 174 & 266 & 617 & 1.7 & 4.5 & 3.1 & 31 & - \\
\hline
\end{tabular}

a) and b) : Surface coverage and \% of desorption estimated according experimental part

c) Interfacial CuAAC click-chemistry was carried out using $\mathrm{CuSO}_{4} /$ Ascorbic acid $^{2}$

- means not determined

or chemically linked to the PLA core via triazole rings (clicked NPS) These triazole rings were in situ produced due to the interfacial CUAAC occurring between some alkyne groups of the surfactant (Dex $-\mathrm{C} \equiv \mathrm{C}^{27}$ or Dex $-\mathrm{C}_{6}{ }^{7}-\mathrm{C} \equiv \mathrm{C}^{10}$ ) and the azido end-function of PLA chains. This led to the synthesis of grafted copolymers at the liquid/liquid interface, as shown in Fig. S5A.

PLA core/PVA shell NPs were formulated using commercial PLA ${ }^{\text {Aldrich }}$ as PVA stabilizer is often reported for the formulation of polyesterbased MCs. As seen in Table 1 (Entry 1), NPs exhibiting $\mathrm{d}(0.5)$ around $180 \mathrm{~nm}$ were easily obtained. After formulation, washing and freeze-drying, these NPs were then dissolved in DMSO- $d_{6}$ to evaluate the PVA surface coverage $\left(\Gamma_{\mathrm{PVA}}\right)$ according equation $7 . \Gamma_{\mathrm{PVA}}$ was estimated to be around $3.3 \mathrm{mg} / \mathrm{m}^{2}$, which indicates that PVA was adsorbed on the NPs core, thus ensuring the NPs colloidal stability. PLA ${ }^{\text {Aldrich }}$ core $/$ Dex- $\mathrm{C}_{6}$ shell NPs have many times been reported by some of us. For instance, NPs with mean diameter of $160 \mathrm{~nm}$ and dextran surface coverage $\left(\Gamma_{\text {Dex }}\right.$, equation 6$)$ between
4.0 and $4.4 \mathrm{mg} / \mathrm{m}^{2}$ were observed when using Dex- $\mathrm{C}_{6}{ }^{14}$ as surfactant $^{50}$. Such characteristics do not depend on the commercial PLA batches we used, (Table 1, Entry 2) when same experimental conditions were carried out.

More novelty is the use of some dextran-based surfactants described earlier to stabilize the PLA/water interface. Dex $-\mathrm{C} \equiv \mathrm{C}^{27}$ and Dex- $\mathrm{C}_{6}{ }^{7}-\mathrm{C} \equiv \mathrm{C}^{10}$ led to NPs with $\mathrm{d}(0.5)$ from 120 to $150 \mathrm{~nm}$ and $\Gamma_{\text {Dex }}$ equal to 2.1 and $2.2 \mathrm{mg} / \mathrm{m}^{2}$, respectively (Table 1, Entries 3 and 5). Such $\Gamma_{\text {Dex }}$ values were lower than those obtained for PLA core/Dex- $C_{6}$ shell, in agreement with the lower hydrophobic character of the alkynyl groups in comparison with the $C_{6}$ chains ${ }^{13,38}$. In some experiments, commercial PLAs were replaced by PLA- $\mathrm{N}_{3}$. While no significant change in $\mathrm{d}(0.5)$ was observed, one can notice an increase of $\Gamma_{\text {Dex }}$ (Table 1, Entry 6). To improve the increase of $\Gamma_{\text {Dex }}$, an interfacial CuAAC click-chemistry was carried out with the $\mathrm{E} / \mathrm{E}$ process. $\mathrm{CuSO}_{4} / \mathrm{AAsc}$ was selected in the present study as it was proved the most efficient catalyst system to reach higher click 
chemistry conversion $(51 \%)^{37}$. With this interfacial CuACC, $\Gamma_{\text {Dex }}$ were increased up to 4.3 and $6.2 \mathrm{mg} / \mathrm{m}^{2}$ when using Dex- $\mathrm{C} \equiv \mathrm{C}^{27}$ and Dex$\mathrm{C}_{6}{ }^{7}-\mathrm{C} \equiv \mathrm{C}^{10}$ as surfactant, respectively (Table 1 , Entries 4 and 7 ). Depending on the surfactant, and considering the same click chemistry conversion, the grafted copolymers produced from Dex$\mathrm{C} \equiv \mathrm{C}^{27}$ at the liquid/liquid interface would be more hydrophobic, then soluble in the organic phase, than those produced from Dex$\mathrm{C}_{6}{ }^{7}-\mathrm{C} \equiv \mathrm{C}^{10}$ (Fig. S5A). This phenomenon could explain the small increase (around $60 \mathrm{~nm}$ ) of $\mathrm{d}(0.5)$ observed between the two clicked-NPs.

As expected, Dex- $\mathrm{N}^{+11}$ didn't have surfactant properties strong enough to stabilize the liquid/liquid interface during the formulation process. The surfactant property of such Dex- $\mathrm{N}^{+11}$ was enhanced by grafting $\mathrm{C}_{6}$ chains to produce Dex- $\mathrm{N}^{+11}-\mathrm{C}_{6}{ }^{14}$. With this ammonium-functionalized hydrophobized dextran surfactants, NPs with $\mathrm{d}(0.5)$ around $270 \mathrm{~nm}$ were obtained, exhibiting a $\Gamma_{\text {Dex }}$ equal to $4.5 \mathrm{mg} / \mathrm{m}^{2}$. NaCl aqueous phase $\left(\mathrm{CH}_{2} \mathrm{Cl}_{2}\right.$-saturated $)$ instead of $\mathrm{CH}_{2} \mathrm{Cl}_{2}$-saturated water within the $\mathrm{E} / \mathrm{E}$ process was nevertheless here required to screen the surface charge of the surfactant and to formulate NPs.

\section{NPs shell stability}

The colloidal stability of NPs covered with dextran stabilizers in $\mathrm{NaCl}$ medium was often proved by some of $\mathrm{us}^{13,14,37,38}$. But, in the present study, SDS, an anionic drastic competitive surfactant, was used to evaluate the stability of NPs shell Desorption of polymers by SDS has already been reported to evaluate the strength of polymers adsorption ${ }^{51-54}$. We recently proved that the physically absorbed dextran shell onto PLAcore of $\mathrm{NPs}^{13,37}$ cannot ensure the shell stability against SDS. In the present study the same destabilization of dextran-based shell is also observed in case of non-clicked PLA-based NPs. Indeed, 85 to $100 \%$ of the neutral dextran-based shell were desorbed in the presence of SDS (Table 1, Entries 2,3,5,6). The desorption yield was estimated from ${ }^{1} \mathrm{H}$ NMR spectrum (Fig. S6) using equation 8 . However, only $31 \%$ of shell was desorbed in case of positive charged shell $\left(\right.$ Dex $\left.-\mathrm{N}^{+11}-\mathrm{C}_{6}{ }^{14}\right)$. This interesting result may be attributed to the possible strong ionic interactions between the positive ammonium groups of the stabilizer and the negative sulphate of SDS instead of the stabilizer desorption. To date, we have no more explanation. From Table 1, we also proved that adsorbed PVA (Entry 1) was not sufficiently stable versus SDS treatment.

In case of clicked NPs (Table 1, Entries 4 and 7), characteristic peaks of the dextran-derivative were still present on ${ }^{1} \mathrm{H} N M R$ spectrum after SDS treatment (Fig. S6). We can notice a clear reduction of the desorption in the case of clicked NPs, due to the triazole ring linkages (Fig. S5A) ensuring the stability of the shell onto the core. Indeed, as shown in Table 1, only 21 (48) wt\% of Dex- $C \equiv C^{27}$ (Dex- $C_{6}{ }^{7}-C \equiv C^{10}$ ) were desorbed by the SDS treatment. These results are in good agreement with other ones previously reported ${ }^{37}$. These low, but not total, desorption can be explained by the entanglement of dextran- based surfactant chains into the shell or by the physical adsorption of these chains onto the PLA core, which were eliminated by SDS treatment ${ }^{37}$. Covalently linked alkynated dextran-based stabilizer to the core, according to Fig. S5A, was not desorbed by SDS.

These shell stabilities were also evaluated by treatment with the culture medium. As proteins present in the culture medium are moderate competitive amphiphiles than SDS, the treatment with culture medium was longer ( 8 days versus one day) than that with SDS, and carried out at $37^{\circ} \mathrm{C}$. According to results shown in Table 1 , one can easily see that physically adsorbed dextran-based surfactant was desorbed in the culture medium. This desorption was reduced after carrying the in situ CuAAC within the NPs formulation process and the explanation is the same than above. In case of Entry 7, the desorption was found higher with the culture medium than with SDS, certainly due to the longer time of treatment.

\section{MCs formulation}

According to the literature, most biodegradable polyester-based MCs are formulated using PVA as surfactant with the E/E process ${ }^{29-}$ ${ }^{31,33}$. To the best of our knowledge, only two studies reported the formulation of polyester-based MCs covered with a chitosan shell. Lao et $a l^{55}$ reported the formulation of PLA-based MCs using PVA as stabilizer. Then, such MCs were immersed in a basic medium to obtain a carboxyl groups-functionalized MCs' surface, which interacted with chitosan to produce chitosan-covered PLA MCs. Privalova et al. $^{29}$ formulated PLA-based MCs exhibiting a chitosanderivative shell covalently linked to the core, thus controlling their surface characteristics.

As described above, the aim of the present investigation is focused on the substitution of PVA with dextran derivatives (Dex $-\mathrm{C}_{6}{ }^{14}$, Dex $-\mathrm{C} \equiv \mathrm{C}^{27}$, Dex $-\mathrm{C}_{6}{ }^{7}-\mathrm{C} \equiv \mathrm{C}^{10}$, Dex $-\mathrm{N}^{+11}-\mathrm{C}_{6}{ }^{14}$, Dex $-\mathrm{N}^{+11}-\mathrm{C} \equiv \mathrm{C}^{24}$ ) to cover PLA-based MCs. By this way, fully in vivo biodegradable dextrancovered PLA-based MCs are expected to be formulated. Such fully biodegradable MCs could be injected into the body after MSCs culture, without requiring trypsinization step to detach and separate cells from the MCs. MCs used for cells culture must have a curve radius of surface low enough to promote cells adhesion. For this reason, most of the commercial MCs have an average size between 100 and $400 \mu \mathrm{m} .{ }^{17,25,55,56}$ Therefore, the dextran-covered PLA-based MCs should have diameters in an equivalent range of size.

As shown in the previous paragraph dealing with NPs, we demonstrated that physically adsorbed PVA or dextran-based surfactant are fully desorbed in the presence of competitive surfactant (SDS or proteins of the culture medium). Biodegradable MCs covered with physically adsorbed PVA or dextran-based surfactant can show the same features, which could be quite an issue for biomedical applications. To enhance the NPs shell stability, 
we carried out an in situ interfacial CuAAC to chemical link the shell onto the core according several triazole rings formation (Fig. S5A). Hence, we developed an E/E process to formulate biodegradable clicked or non-clicked MCs with a controlled size and surface chemistry. Finally, we also formulated MCs covered with a fluorescent dextran derivative to qualitatively study this shell stability.

Several preliminary attempts were done to formulate such MCs with mean diameter between 150 to $350 \mu \mathrm{m}$, using a $250 \mathrm{~mL}$ glass reactor and a mechanical stirrer with a 4 blades propeller (Fig. 4).

To reach this range of size, various parameters were adjusted, as

Table 2: Characteristics of MCs (formulated using a solution of PLA in $\mathrm{CH}_{2} \mathrm{Cl}_{2}\left(50 \mathrm{~g} \mathrm{~L}^{-1}\right)$ and a solution of surfactant $\left(5 \mathrm{~g} \mathrm{~L}^{-1}\right)$ in $\mathrm{CH}_{2} \mathrm{Cl}_{2}$ saturated water). $D=1.2 \mathrm{~cm}$.

\begin{tabular}{|c|c|c|c|c|c|c|c|c|}
\hline Entry & Click & $\mathrm{R}_{\text {stirring }}(\mathrm{rpm})$ & Core & Surfactant & $\mathrm{d}(0.1)(\mu \mathrm{m})$ & $d(0.5)(\mu m)$ & $d(0.9)(\mu \mathrm{m})$ & Span \\
\hline 1 & NO & 310 & $\mathrm{PLA}^{\text {Aldrich }}$ & Dex- $C_{6}{ }^{14}$ & 146 & 194 & 267 & 0.6 \\
\hline 2 & NO & 310 & PLA $A^{\text {Natureplast }}$ & Dex-C ${ }_{6}{ }^{14}$ & 162 & 216 & 283 & 0.6 \\
\hline 3 & NO & 310 & $\mathrm{PLA} \mathrm{N}_{3}$ & Dex- ${ }_{6}{ }^{14}$ & 167 & 234 & 317 & 0.6 \\
\hline $4^{\text {a) }}$ & NO & 350 & $\mathrm{PLA}^{\text {Natureplast }}$ & Dex-C ${ }_{6}{ }^{14}$ & 251 & 336 & 446 & 0.6 \\
\hline $5^{\text {a) }}$ & NO & 450 & PLA ${ }^{\text {Natureplast }}$ & Dex-C ${ }_{6}{ }^{14}$ & 157 & 221 & 297 & 0.6 \\
\hline $6^{\text {a) }}$ & NO & 550 & PLA ${ }^{\text {Natureplast }}$ & Dex-C ${ }_{6}{ }^{14}$ & 102 & 141 & 204 & 0.7 \\
\hline 7 & NO & 400 & PLA ${ }^{\text {Aldrich }}$ & Dex $-C \equiv C^{27}$ & 118 & 156 & 212 & 0.6 \\
\hline 8 & NO & 400 & $\mathrm{PLA}^{\text {Natureplast }}$ & Dex-C $\equiv C^{27}$ & 133 & 186 & 267 & 0.7 \\
\hline 9 & NO & 400 & $\mathrm{PLA} \mathrm{N}_{3}$ & Dex $-C \equiv C^{27}$ & 114 & 155 & 203 & 0.6 \\
\hline $10^{c)}$ & YES & 400 & PLA N $_{3}$ & Dex $-C \equiv C^{27}$ & 143 & 237 & 316 & 0.7 \\
\hline $11^{\text {a) }}$ & NO & 550 & PLA ${ }^{\text {Natureplast }}$ & Dex-C $\equiv C^{27}$ & 98 & 161 & 281 & 1.1 \\
\hline 12 & NO & 370 & PLA ${ }^{\text {Aldrich }}$ & Dex- $C_{6}{ }^{7}-C \equiv C^{10}$ & 130 & 170 & 223 & 0.5 \\
\hline 13 & NO & 370 & $\mathrm{PLA} \mathrm{N}_{3}$ & Dex- $C_{6}{ }^{7}-C \equiv C^{10}$ & 131 & 173 & 224 & 0.5 \\
\hline $14^{c)}$ & YES & 370 & $\mathrm{PLA} \mathrm{N}_{3}$ & Dex- $C_{6}{ }^{7}-C \equiv C^{10}$ & 135 & 239 & 332 & 0.8 \\
\hline $15^{b)}$ & NO & 410 & PLA ${ }^{\text {Natureplast }}$ & Dex- $-\mathrm{N}^{+11}-\mathrm{C}_{6}{ }^{14}$ & 83 & 113 & 244 & 1.4 \\
\hline $\begin{array}{l}16 \\
a, b)\end{array}$ & NO & 500 & PLA ${ }^{\text {Natureplast }}$ & Dex- $-\mathrm{N}^{+11}-\mathrm{C}_{6}{ }^{14}$ & 92 & 123 & 163 & 0.6 \\
\hline $17^{\text {b) }}$ & NO & 410 & PLA ${ }^{\text {Natureplast }}$ & Dex- $-N^{+11}-C \equiv C^{24}$ & 118 & 192 & 340 & 1.1 \\
\hline 18 & NO & 400 & PLA N $_{3}$ & Dex- $C \equiv C^{25}$-Coumarin ${ }^{1.5}$ & 114 & 146 & 189 & 0.5 \\
\hline $19^{c)}$ & YES & 450 & PLA N $_{3}$ & Dex- $C \equiv C^{25}$-Coumarin ${ }^{1.5}$ & 106 & 185 & 338 & 1.2 \\
\hline
\end{tabular}

a) Entries have been carried out using $20 \mathrm{~mL}$ of organic phase (100 g L $\mathrm{L}^{-1}$ of PLA) and $200 \mathrm{~mL}$ of aqueous phase (5 $\mathrm{g} \mathrm{L}^{-1}$ of surfactant) the nature of the organic solvent, the concentrations of the organic and the aqueous phases, the rate of stirring, the volume ratio between these two phases and the distance (D) between the blades of the propeller and the bottom of the reactor. The best results were obtained at $40^{\circ} \mathrm{C}$ using $4 \mathrm{~mL}$ of PLA dissolved in $\mathrm{CH}_{2} \mathrm{Cl}_{2}(50 \mathrm{~g} \mathrm{~L}$ ${ }^{1}$ ), $40 \mathrm{~mL}$ aqueous phase $\left(5 \mathrm{~g} \mathrm{~L}^{-1}\right.$ of dextran derivative in $\mathrm{CH}_{2} \mathrm{Cl}_{2}$ saturated water), D fixed to $1.2 \mathrm{~cm}$. As shown in Table 2 (Entries 13 ), when using stirring rate equal to $310 \mathrm{rpm}$, the formulation of PLA core/Dex- $\mathrm{C}_{6}{ }^{14}$ shell MCs was easily achieved. The batch of PLA seemed to not significantly 
b) $0.5 \mathrm{M} \mathrm{NaCl} \mathrm{CH}_{2} \mathrm{Cl}_{2}$-saturated were used instead of water $\mathrm{CH}_{2} \mathrm{Cl}_{2}$-saturated.

c) Interfacial CuAAC click-chemistry was carried out using $\mathrm{CuSO}_{4} /$ Ascorbic acid.

influence the mean diameter as $d(0.5)$ was comprised between 200 and $235 \mu \mathrm{m}$. All these MCs were characterized by monomodal and quite narrow size distributions (Span < 1). Spherical morphology was confirmed by SEM observations (Fig. 5). As similar results were observed for all PLA batches, following entries were carried out using batches equally. For each entry described above, about 150 $\mathrm{mg}$ of MCs were finally obtained after purification. Nevertheless, a higher mass of MCs is required for MSCs culture. Consequently, we tried to scale up the process within the same reactor and same propeller. For this purpose, the volume of each phase was increased: from 4 to $20 \mathrm{~mL}$ for the organic phase and from 40 to $200 \mathrm{~mL}$ for the aqueous phase. Moreover, the PLA concentration was fixed at $100 \mathrm{~g} \mathrm{~L}^{-1}$ instead of $50 \mathrm{~g} \mathrm{~L}^{-1}$. All the other parameters remained identical to the ones used before except the stirring rate. Indeed, as shown in Table 2 (Entry 4), when using a quite similar stirring rate (350 vs $310 \mathrm{rpm}$ ), bigger MCs were obtained, while having quite narrow size distributions and spherical morphology (Fig. 5). Increasing this stirring rate to $450 \mathrm{rpm}$ (550 rpm) allowed decreasing the organic 

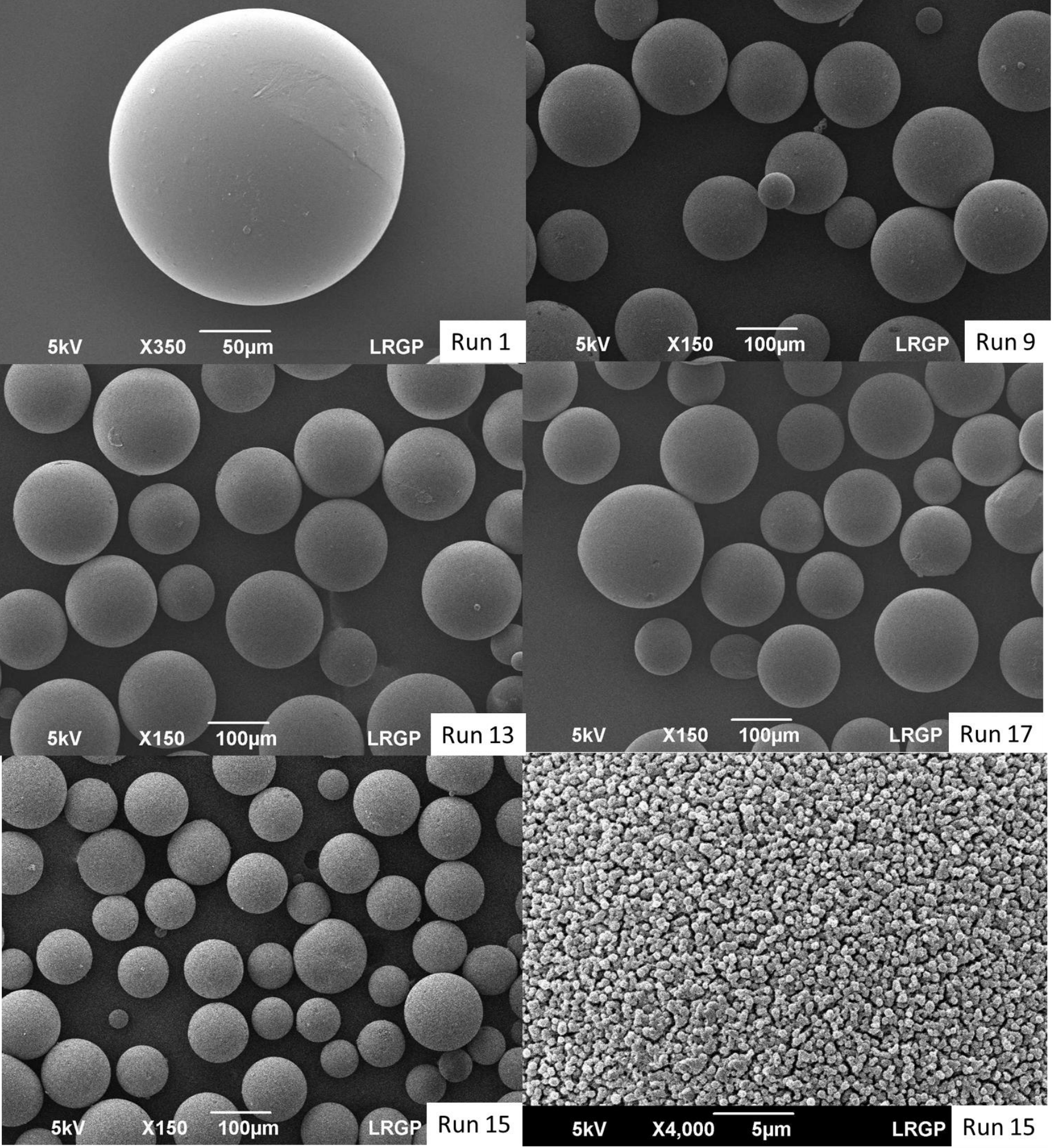

Fig. 5: Scanning electronic microscopy pictures of several MCS (see Table 2). Magnification and scale bar are done on the pictures.

phase droplet size. By this way, MCs exhibiting $\mathrm{d}(0,5)$ around 220 (140) $\mu \mathrm{m}$ were formulated (Table 2, Entries 5 and 6). While not really optimized, increasing the stirring rate of $150 \mathrm{rpm}$ within the scaled-up protocol allowed us to get a large amount of biodegradable MCs in the required size range. Indeed, with these new experimental conditions, about $1.5 \mathrm{~g}$ of MCs were easily formulated.

As the chemical and physical properties of a surface influence cells adhesion, we chose to formulate MCs with different dextran derivatives (Dex- $\mathrm{C} \equiv \mathrm{C}^{27}$, Dex- $\mathrm{C}_{6}{ }^{7}-\mathrm{C} \equiv \mathrm{C}^{10}$, Dex- $\mathrm{N}^{+11}-\mathrm{C}_{6}{ }^{14}$, 
Dex- $\left.\mathrm{N}^{+11}-\mathrm{C} \equiv \mathrm{C}^{24}\right)$. Indeed, electrostatic, van der Waals and hydrophobic forces mediate the nonspecific cells adhesion on surface. ${ }^{29,39,40,57}$ Due to various surfactant properties of the dextran derivatives we used, the stirring rate was varied to reach MCs size in the required range. Consequently, using Dex $-\mathrm{C} \equiv \mathrm{C}^{27}$, stirring rate was increased to $400 \mathrm{rpm}$ as shown in Table 2. Whatever the PLA batch, $d(0,5)$ from 155 to $185 \mu \mathrm{m}$ was observed (Entries 7-9). With the scaled-up protocol, increasing the stirring rate to $550 \mathrm{rpm}$ led us to observe the formulation of large quantity of MCs with $d(0,5)$ equal to $160 \mu \mathrm{m}$ (Entry 11). Using Dex- $\mathrm{C}_{6}{ }^{7}-\mathrm{C} \equiv \mathrm{C}^{10}$ as surfactant allowed us to formulate MCs with $\mathrm{d}(0,5)$ around $170 \mu \mathrm{m}$ (Entries 12-13) when using stirring rate of $370 \mathrm{rpm}$.

Ammonium-functionalized dextran derivatives (Dex- $\mathrm{N}^{+11}-\mathrm{C}_{6}{ }^{14}$ Dex- $\mathrm{N}^{+11}-\mathrm{C} \equiv \mathrm{C}^{24}$ ) were slightly more difficult to use in the $\mathrm{E} / \mathrm{E}$ process. At first, Dex- $\mathrm{N}^{+11}-\mathrm{C}_{6}{ }^{14}$ was dissolved in Milli-Q $\mathrm{CH}_{2} \mathrm{Cl}_{2}$ saturated water. The resulting MCs were characterized by a multimodal population with too large diameters for our application (results not shown). Due to their positive charges, Dex $-\mathrm{N}^{+11}-\mathrm{C}_{6}{ }^{14}$ chains repulse each other in water and are not able to conveniently stabilize the droplets during the process. The addition of $\mathrm{NaCl}$ in the aqueous phase was necessary to screen the electrostatic interactions between stabilizer chains. After several attempts, we chose to use $0.5 \mathrm{M} \mathrm{NaCl} \mathrm{CH}_{2} \mathrm{Cl}_{2}$-saturated aqueous phase instead of $\mathrm{CH}_{2} \mathrm{Cl}_{2}$-saturated milliQ water and fixed the stirring rate at $410 \mathrm{rpm}$. Without optimization of these last two conditions, MCs with $d(0,5)$ around $115 \mu \mathrm{m}$ (Entry 15) were obtained. Unexpectedly, the surface of these MCs is not smooth as shown on Fig 5, but currently we have no explanation for this surface topography change. Decreasing the stirring rate will certainly produce bigger MCs. Consequently, we chose to produce a larger batch of ammoniumfunctionalized MCs (Entry 16) by using stirring rate of $500 \mu \mathrm{m}$. With these conditions, $d(0.5)$ equal to $123 \mu \mathrm{m}$ was measured. Dex $-\mathrm{N}^{+11}$. $\mathrm{C} \equiv \mathrm{C}^{24}$, which carries ammonium groups and alkyne functions proved to be very difficult to use. While several attempts were made, only one batch of MCs covered with this stabilizer could be formulated with $d(0,5)=193 \mu \mathrm{m}$ (Entry 17).

As explained in the previous paragraph dealing with NPs, we demonstrated that physically adsorbed PVA or dextran-based surfactants are fully desorbed in the presence of competitive surfactant (SDS or proteins of the culture medium). Biodegradable MCs covered with physically adsorbed PVA or dextran-based surfactant can show the same features, which could be quite an issue for biomedical applications. Similarly to NPs, we developed an E/E process to formulate biodegradable clicked or non-clicked MCs with a controlled size and surface chemistry. Indeed, some of the dextran-based surfactants we used were grafted with alkyne functions, which allowed us to carry out an interfacial in situ CUAAC with the E/E process when using PLA- $\mathrm{N}_{3}$ as made for NPs. Hence, with Dex $-\mathrm{C} \equiv \mathrm{C}^{27}$, we obtained clicked MCs exhibiting a $\mathrm{d}(0,5)$ around $240 \mu \mathrm{m}$ (Entry 10) that is $80 \mu \mathrm{m}$ bigger that the MCs obtained in the same conditions but without interfacial CuAAC (Entry 9). With Dex$\mathrm{C}_{6}{ }^{7}-\mathrm{C} \equiv \mathrm{C}^{10}$ as surfactant, carrying in situ CuAAC reaction led us to formulate $240 \mu \mathrm{m}$ average diameter MCs (Entry 14) instead of 170 $\mu \mathrm{m}$ for MCs formulated with the same surfactant but without CuAAC (Entries 12 and 13). Currently, we have no explanation for this diameter increase. Nevertheless, all the clicked MCs are characterized by a monomodal and narrow sized distribution, with sizes comprised in the required diameter range. Moreover, and according to our previous results on the efficiency of the in situ CUAAC during NPs formulation (efficiency around $50 \%{ }^{37}$ ), we believe that the alkyne-functionalized dextran covered MCs we produced are exhibiting unreacted alkyne functions. These functions may allow further MCs surface modification to enhance MSCs adhesion, if necessary.

\section{Fluorescent MCs}

We also formulated MCs covered by a fluorescent dextran derivative (Dex- $\mathrm{C} \equiv \mathrm{C}^{25}$-Coumarin ${ }^{1.5}$ ) to qualitatively study the shell stability of the MCs. As this surfactant is also carrying alkyne groups, we formulated non-clicked MCs (the stabilizer is physically adsorbed onto the core, Entry 18 , Table 2 ) or clicked MCs (Entry 19). Such fluorescent MCs were characterized by a monomodal distribution with mean diameter in the required size range (around 145 and $185 \mu \mathrm{m}$, Table 2). More precisely, an increase of $40 \mu \mathrm{m}$ and a larger population (Span=1.2) were observed when carrying out the in situ CuAAC between the PLA- $\mathrm{N}_{3}$ and the Dex-C $\equiv \mathrm{C}^{25}$-Coumarin ${ }^{1.5}$. Fig. 6 presents MEB images of clicked and unclicked MCs. As shown in Fig. 6 and Fig S7, unclicked MCs exhibit spherical shape and smooth surface. In contrast, the clicked MCs exhibit non-rigorous surface, but their shape remain spherical. Such surface may be attributed to destabilization of the MCs surface during the in situ CuAAC reaction that occurred at the liquid/liquid interface, which lead to the deformation of the interface as schematically drawn in Fig. S5B.

Carrying several coumarin groups, the Dex- $\mathrm{C} \equiv \mathrm{C}^{25}-$ Coumarin ${ }^{1.5}$ and consequently the shell of these two $\mathrm{MC}$ batches were fluorescent, which was useful to indirectly evaluate the shell stability of these MCs. Before the SDS treatment, these two MC batches have been observed by confocal microscopy (Fig. 6). In both cases, a fluorescent shell of Dex- $\mathrm{C} \equiv \mathrm{C}^{25}$-Coumarin ${ }^{1.5}$ was observed around a "black" non-fluorescent PLA core. These results show that the fluorescent dextran-derivatives (Dex-C $=\mathrm{C}^{25}-$ Coumarin $^{1.5}$ or the fluorescent grafted copolymer produced by CUAAC) are only present on the surface of the MCs, and not into the core, thus ensuring their colloidal stability. Then, both MCs were left in contact with SDS to study their shell stability. In case of non-clicked MCs (Entry 18, Table 2) the physically adsorbed fluorescent shell was not stable towards SDS, as no more fluorescent shell was observed after the SDS treatment (Fig. 6), while still observing the presence of MCs. This observation agrees with the results described above when studying NPs. In case of clicked MCs (Entry 19, Table 2), a fluorescent shell was still observed at the surface (Fig. 6). This result confirms that Dex- $C \equiv C^{25}$-Coumarin ${ }^{1.5}$ was covalently linked to the PLA- $\mathrm{N}_{3}$ core via 
the in situ CUAAC reaction during the E/E process and that increases the shell stability.

A)
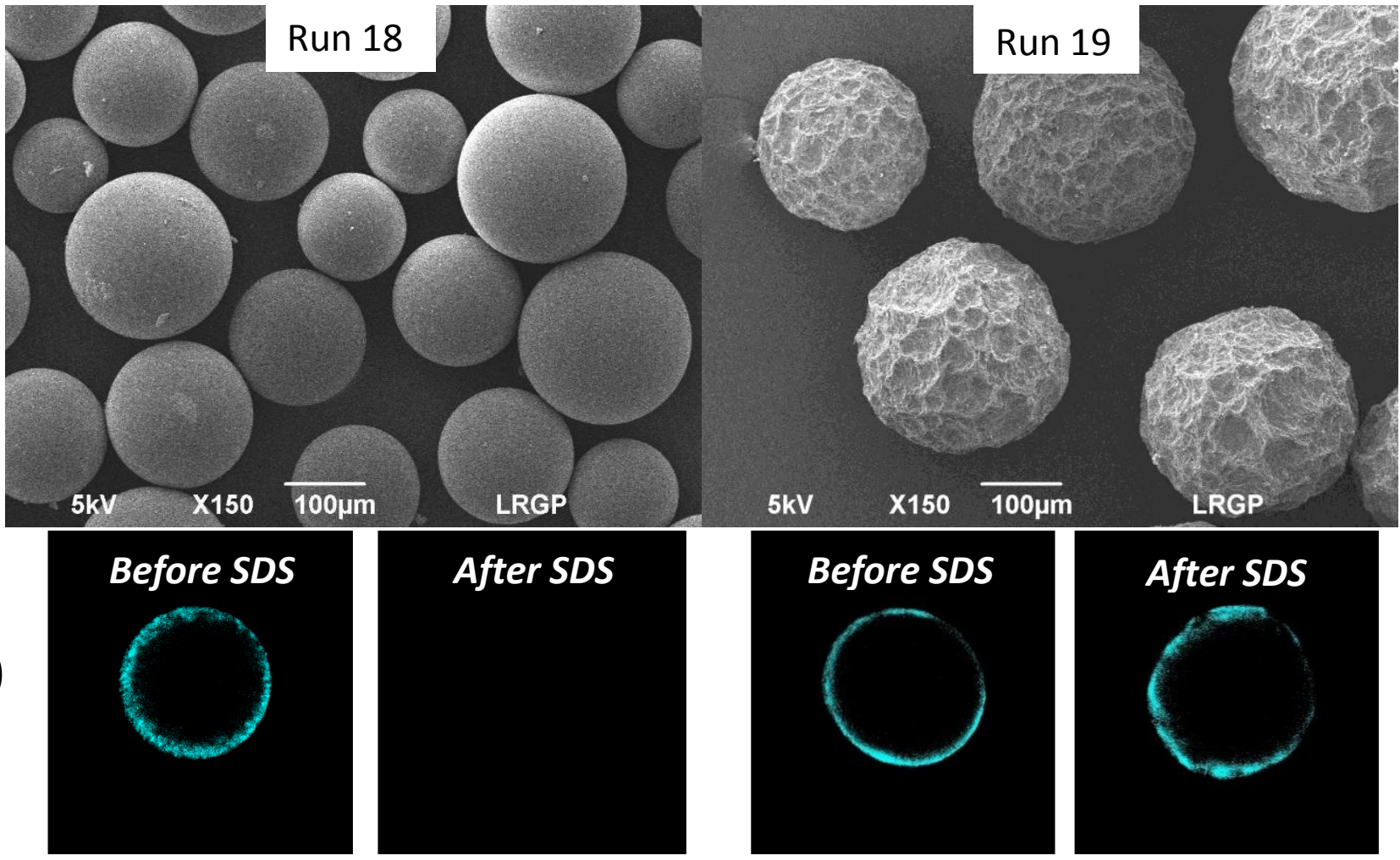

Fig. 6: A) Scanning electronic microscopy pictures of fluorescent MCS (Entries 18 and 19, Table 2). Magnification and scale bar are done on the pictures. B) Confocal laser scanning microscopy of the same MCs, before and after the SDS treatment.

\section{Conclusions}

Several dextran derivatives were synthesized and used as surfactants within an E/E process to formulate fully in vivo bioresorbable dextran-covered PLA-based MCs. Some of these surfactants were carrying alkyne groups, whereas others were bearing ammonium or fluorescent moieties. In some cases, the polysaccharide stabilizer was in fine physically adsorbed onto the PLA core of the MCs. In other cases, the polysaccharide shell was linked to the core via an in-situ CuAAC clickchemistry carried out during the E/E process. Whatever the stabilizer, spherical MCs with narrow size distribution and mean diameters from 115 to $335 \mu \mathrm{m}$ were obtained.

The stability of such particles coverage in the presence of competitive surfactants was quantitatively studied with NPs with the same chemical composition than MCs. Results showed that physically adsorbed stabilizers at the NPs surface were completely desorbed by a competitive surfactant like SDS. A high desorption of the shell was also noticed after the NPs were treated with the MSC culture medium. These results indicated that proteins contained in the culture medium possess strong enough surface-active properties to desorb dextran derivatives chains from particles surface. However, this shell desorption could be quite reduced in the case of clicked NPs, thanks to the in situ CuAAC reaction carried out during the E/E process. Shell stability of MCs was also qualitatively studied using a fluorescent dextran-based surfactant. In agreement with the NPs results, shell stability was strongly increased when the fluorescent dextran derivative was chemically linked to the PLA core.

To the best of our knowledge, this is the first paper dealing with MCs surface stability which plays an essential role on MSCs adhesion and evolution. Therefore, such partial desorption of MCs shell could be quite an issue during MSCs expansion. However, clicked MCs, which possess a better shell stability, could allow a better control the MCs surface chemistry all over the cell growth process and thus, ensure better cell culture conditions.

\section{Acknowledgements}

The authors express their highest gratitude to i) Caroline Sejil for SEC measurements and Olivier Fabre for NMR measurements ii) Jean-François Rémy (Laboratoire Réactions et Génie des Procédés, UMR 7274, Nancy, France) for Scanning electron microscope and iii) Dr. Catherine Malaplate-Armand (Unité de Recherche Animal et 
Fonctionnalités des Produits Animaux, Nancy, France) for confocal laser scanning microscopy. J.L. Six and A. Roy acknowledge support from ANR-14-CE07-0022-03 (STEMCellREACTOR) for funding and post-doctoral fellowship, respectively.

\section{References}

1 A. C. Rice-Ficht, A. M. Arenas-Gamboa, M. M. Kahl-McDonagh and T. A. Ficht, Curr. Opin. Microbiol., 2010, 13, 106-112.

2 K. M. Ho, W. Y. Li, C. H. Wong and P. Li, Colloid Polym. Sci., 2010, 288, 1503-1523.

3 R. Vehring, Pharm. Res., 2008, 25, 999-1022.

4 M. Gaumet, A. Vargas, R. Gurny and F. Delie, Eur. J. Pharm. Biopharm., 2008, 69, 1-9.

5 M. T. Gokmen and F. E. Du Prez, Prog. Polym. Sci., 2012, 37, 365-405.

6 M. van de Weert, W. E. Hennink and W. Jiskoot, Pharm. Res., 2000, 17, 1159-1167.

7 W. Jiang, R. Gupta, M. Deshpande and S. Schwendeman, Adv. Drug Deliv. Rev., 2005, 57, 391-410.

8 K. S. Soppimath, T. M. Aminabhavi, A. R. Kulkarni and W. E. Rudzinski, J. Controlled Release, 2001, 70, 1-20.

9 J. Panyam and V. Labhasetwar, Adv. Drug Deliv. Rev., 2003, 55 329-347.

10 A. Kumari, S. K. Yadav and S. C. Yadav, Colloids Surf. B Biointerfaces, 2010, 75, 1-18.

11 D. Chognot, M. Léonard, J.-L. Six and E. Dellacherie, Colloids Surf. B Biointerfaces, 2006, 51, 86-92.

12 D. Chognot, J.-L. Six, M. Léonard, E. Dellacherie, B. Faivre, F. Bonneaux and C. Vigneron, J. Bioact. Compat. Polym., 2008, 23, 49-68.

13 M. Laville, J. Babin, I. Londono, M. Legros, C. Nouvel, A. Durand, R. Vanderesse, M. Leonard and J.-L. Six, Carbohydr. Polym., 2013, 93, 537-546.

14 C. Gavory, A. Durand, J.-L. Six, C. Nouvel, E. Marie and M. Leonard, Carbohydr. Polym., 2011, 84, 133-140.

15 C. Nouvel, J. Raynaud, E. Marie, E. Dellacherie, J.-L. Six and A. Durand, J. Colloid Interface Sci., 2009, 330, 337-343.

16 M. Riffault, J.-L. Six, P. Netter, P. Gillet and L. Grossin, Pharm. Res., 2015, 32, 3886-3898.

17 A. K.-L. Chen, S. Reuveny and S. K. W. Oh, Biotechnol. Adv., 2013, 31, 1032-1046.

18 A. I. Caplan, J. Cell. Physiol., 2007, 213, 341-347.

19 A. I. Caplan and S. P. Bruder, Trends Mol. Med., 2001, 7, 259264.

20 F. P. Barry and J. M. Murphy, Int. J. Biochem. Cell Biol., 2004, 36 , 568-584.

21 D. Baksh, L. Song and R. S. Tuan, J. Cell. Mol. Med., 2004, 8, 301-316.

22 N. L. Davie and D. A. Brindley, Development, 2012, 85, 100.

23 S. Jung, K. M. Panchalingam, R. D. Wuerth, L. Rosenberg and L. A. Behie, Biotechnol. Appl. Biochem., 2012, 59, 106-120.
24 Y. Nie, V. Bergendahl, D. J. Hei, J. M. Jones and S. P. Palecek, Biotechnol. Prog., 2009, 25, 20-31.

25 S. Sart, S. N. Agathos and Y. Li, Biotechnol. Prog., 2013, 29, 1354-1366.

26 C. Ferrari, E. Olmos, F. Balandras, N. Tran, I. Chevalot, E. Guedon and A. Marc, Appl. Biochem. Biotechnol., 2014, 172, 10041017.

27 L. Yang, F. Cheng, T. Liu, J. R. Lu, K. Song, L. Jiang, S. Wu and W. Guo, Biomed. Mater., 2012, 7, 035003.

28 T. H. Shin, S. Lee, K. R. Choi, D. Y. Lee, Y. Kim, M. J. Paik, C. Seo, S. Kang, M. S. Jin, T. H. Yoo, S. H. Kang and G. Lee, Sci. Rep., , DOI:10.1038/s41598-017-01315-0.

29 A. Privalova, E. Markvicheva, C. Sevrin, M. Drozdova, C. Kottgen, B. Gilbert, M. Ortiz and C. Grandfils, J. Biomed. Mater. Res. A, 2015, 103, 939-948.

30 K. D. Newman and M. W. McBurney, Biomaterials, 2004, 25, 5763-5771.

31 C. Bouffi, O. Thomas, C. Bony, A. Giteau, M.-C. Venier-Julienne, C. Jorgensen, C. Montero-Menei and D. Noël, Biomaterials, 2010, 31, 6485-6493.

32 J. Li, A. T.-L. Lam, J. P. W. Toh, S. Reuveny, S. K.-W. Oh and W. R. Birch, Biomed. Microdevices, , DOI:10.1007/s10544-015-0010-6.

33 A. Shekaran, A. Lam, E. Sim, L. Jialing, L. Jian, J. T. P. Wen, J. K. Y. Chan, M. Choolani, S. Reuveny, W. Birch and S. Oh, Cytotherapy, 2016, 18, 1332-1344.

34 A. T.-L. Lam, J. Li, J. P.-W. Toh, E. J.-H. Sim, A. K.-L. Chen, J. K.-Y. Chan, M. Choolani, S. Reuveny, W. R. Birch and S. K.-W. Oh, Cytotherapy, 2017, 19, 419-432.

35 M. Morille, T. Van-Thanh, X. Garric, J. Cayon, J. Coudane, D. Noël, M.-C. Venier-Julienne, C. N. Montero-Menei, J. Control. Release, 2013, 170, 99-110.

36 Y. Guo, M. Zhou, S. K. Cui and N. Nian, J. Environ. Sci. Health Part A, 2013, 48, 518-525.

37 K. Poltorak, A. Durand, M. Léonard, J.-L. Six and C. Nouvel, Colloids Surf. Physicochem. Eng. Asp., 2015, 483, 8-17.

38 M. El Founi, S. M. A. Soliman, R. Vanderesse, S. Acherar, E. Guedon, I. Chevalot, J. Babin and J.-L. Six, J. Colloid Interface Sci., 2018, 514, 289-298.

39 D. W. Levine, D. I. C. Wang and W. G. Thilly, Biotechnol. Bioeng., 1979, 21, 821-845.

40 S. Reuveny, A. Mizrahi, M. Kotler and A. Freeman, Biotechnol. Bioeng., 1983, 25, 469-480.

41 S. M. A. Soliman, L. Colombeau, C. Nouvel, J. Babin and J.-L. Six, Carbohydr. Polym., 2016, 136, 598-608.

42 E. Rotureau, E. Marie, E. Dellacherie and A. Durand, Colloids Surf. Physicochem. Eng. Asp., 2007, 301, 229-238.

43 L. Dupayage, C. Nouvel and J.-L. Six, J. Polym. Sci. Part Polym. Chem., 2011, 49, 35-46.

44 C. Duval, C. Nouvel and J.-L. Six, J. Polym. Sci. Part Polym. Chem., 2014, 52, 1130-1138.

45 K. Makiguchi, S. Kikuchi, T. Satoh and T. Kakuchi, J. Polym. Sci. Part Polym. Chem., 2013, 51, 2455-2463.

46 T. Isono, Y. Kondo, I. Otsuka, Y. Nishiyama, R. Borsali, T. Kakuchi and T. Satoh, Macromolecules, 2013, 46, 8509-8518. 
47 N. Sugai, T. Yamamoto and Y. Tezuka, ACS Macro Lett., 2012, 1, 902-906.

48 M. C. Tanzi, P. Verderio, M. G. Lampugnani, M. Resnati, E. Dejana and E. Sturani, J. Mater. Sci. Mater. Med., 1994, 5, 393396.

49 M. Schappacher, M. Le Hellaye, R. Bareille, M.-C. Durrieu and S. M. Guillaume, Macromol. Biosci., 2010, 10, 60-67.

50 C. Rouzes, M. Leonard, A. Durand and E. Dellacherie, Colloids Surf. B Biointerfaces, 2003, 32, 125-135.

51 B. Cattoz, T. Cosgrove, M. Crossman and S. W. Prescott, Langmuir, 2012, 28, 2485-2492.

52 A. M. Blokhus and K. Djurhuus, J. Colloid Interface Sci., 2006, 296, 64-70.

53 R. A. Lauten, A.-L. Kjøniksen and B. Nyström, Langmuir, 2000, $16,4478-4484$.

54 K. Ferji, I. Hamouda, C. Chassenieux, B. Nadal, B. Dubertret, C. Gaillard, E. Nicol, J. Colloid Interface Sci. 2016, 476, 222-229

55 L. Lao, H. Tan, Y. Wang and C. Gao, Colloids Surf. B Biointerfaces, 2008, 66, 218-225.

56 J. Malda and C. G. Frondoza, Trends Biotechnol., 2006, 24, 299304.

57 W. Zheng, W. Zhang and X. Jiang, Adv. Healthc. Mater. 2013, 2, 95-108 